\title{
Catalytic Oxychlorination versus Oxybromination for Methane Functionalization
}

\section{Journal Article}

Author(s):

Zichittella, Guido; Paunović, Vladimir; Amrute, Amol P.; Pérez-Ramírez, Javier

Publication date:

2017-03

Permanent link:

https://doi.org/10.3929/ethz-b-000129624

Rights / license:

In Copyright - Non-Commercial Use Permitted

Originally published in:

ACS Catalysis 7(3), https://doi.org/10.1021/acscatal.6b03600

\section{Funding acknowledgement:}

156107 - Design of oxyhalogenation catalysts for hydrocarbon functionalization (SNF) 


\section{Catalytic Oxychlorination versus Oxybromination for Methane Functionalization}

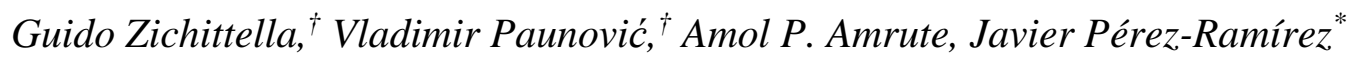

Institute for Chemical and Bioengineering, Department of Chemistry and Applied Biosciences, ETH Zurich, Vladimir-Prelog-Weg 1, 8093 Zurich, Switzerland

KEYWORDS: natural gas upgrading, methane functionalization, halogen chemistry, oxychlorination, oxybromination 


\section{ABSTRACT}

The catalytic oxyhalogenation is an attractive route for the functionalization of methane in a single step. This study investigates methane oxychlorination (MOC) and oxybromination (MOB) in a wide range of conditions over various materials having different oxidation properties to assess the impact of hydrogen halide $(\mathrm{HX}, \mathrm{X}=\mathrm{Cl}, \mathrm{Br})$ on the catalyst performance. The oxyhalogenation activity of the catalysts, ranked as $\mathrm{RuO}_{2}>\mathrm{Cu}-\mathrm{K}-\mathrm{La}-\mathrm{X}>\mathrm{CeO}_{2}>\mathrm{VPO}>\mathrm{TiO}_{2}>$ $\mathrm{FePO}_{4}$, is correlated with their ability to oxidize the hydrogen halide and the gas-phase reactivity of the halogen with methane. The product distribution is found to be strongly dependent on the nature of the catalyst and the type of the halogen. The least reducible $\mathrm{FePO}_{4}$ exhibits a marked propensity to halomethanes $\left(\mathrm{CH}_{3} \mathrm{X}, \mathrm{CH}_{2} \mathrm{X}_{2}\right)$ and the strongly oxidizing $\mathrm{RuO}_{2}$ favors combustion in both reactions, while other systems reveal stark selectivity differences between MOC and MOB. VPO and $\mathrm{TiO}_{2}$ lead to a selective $\mathrm{CH}_{3} \mathrm{Br}$ production in $\mathrm{MOB}$, and pronounced $\mathrm{CO}$ formation in MOC, whereby product distribution was only slightly affected by the variation of the $\mathrm{HX}$ concentration. On contrary, $\mathrm{CeO}_{2}$ and $\mathrm{Cu}$-based catalyst provide a high selectivity to $\mathrm{CH}_{3} \mathrm{Cl}$, but give rise to a marked $\mathrm{CO}_{2}$ formation when $\mathrm{HBr}$ is used as a halogen source. The behavior of the latter systems is explained by the higher energy of the metal-Cl bond compared to the metal-Br, enabling more suppression of the unwanted $\mathrm{CO}$ and $\mathrm{CO}_{2}$ formation when $\mathrm{HCl}$ is used, as also inferred from the more pronounced performance dependence on the HX content in the feed. Extrapolating this result, the highest reported yields of chloromethanes (28\% at $>82 \%$ selectivity) and bromomethanes (20\% at $>98 \%$ selectivity) are attained over $\mathrm{CeO}_{2}$, by adjusting the feed $\mathrm{HX}$ content to curb the $\mathrm{CO}_{2}$ generation. A vis-à-vis comparison of MOC and MOB presented for the first time in this study deepens the understanding of halogen-mediated methane functionalization as a key step towards the design of an oxyhalogenation process. 


\section{INTRODUCTION}

The selective activation of the inert $\mathrm{C}-\mathrm{H}$ bonds in methane, being the principal component of the natural gas, is one of the key challenges in catalysis research. With its abundant reserves, methane offers a huge potential as a feedstock for the manufacture of chemicals and fuels. ${ }^{1-4}$ Nevertheless, over $30 \%$ of the world's natural gas is trapped in small basins and/in remote areas, where its valorization via syngas using existing steam reforming technology is not economical due to its high energy and capital demands. ${ }^{2,5}$ Consequently, less than $10 \%$ of the global annual gas production is currently used for the manufacture of commodities, while $c a$. 3.5\%, a share which is worth ca. 13 billion USD, is flared at oil and gas fields or refineries. ${ }^{5-8}$

Over the last decades, various methane activation routes such as partial oxidation, ${ }^{9}$ oxidative coupling, ${ }^{10-11}$ aromatization, ${ }^{12-13}$ selective oxidation into methanol, ${ }^{14-17}$ and (oxy)halogenation ${ }^{18-}$ 34 have been studied as alternative approaches to steam reforming. Among those, halogenmediated methane functionalization is of particular interest since halogens, such as chlorine or bromine, readily react with methane under moderate reaction conditions $(\sim 1 \mathrm{bar},<800 \mathrm{~K})$ in the presence or absence of a catalyst, yielding methyl halides $\left(\mathrm{CH}_{3} \mathrm{X}, \mathrm{X}=\mathrm{Cl}, \mathrm{Br}\right){ }^{2}$ The latter, isostructural to methanol, are versatile platform molecules and can be readily transformed into a wide spectrum of chemicals and fuels by halogen elimination in the form of hydrogen halide $(\mathrm{HX}) .{ }^{2,35}$ Nevertheless, the real-life implementation of the direct halogenation route necessitates the closing of the halogen cycle by converting HX, liberated in both the halogenation and subsequent elimination step, to $\mathrm{X}_{2}$ e.g. via catalytic oxidation. ${ }^{2,36-38}$ On the other hand, catalytic oxyhalogenation, involving the reaction of methane with HX and oxygen, enables the integration of methane functionalization with HX recovery in a single step. ${ }^{2,34}$ Still, critical challenges will have to be overcome in order to bring this concept from the laboratory to the industrial scale. 
Particularly, the presence of oxygen in the feed leads to the formation of carbon oxides, which might be further promoted due to an enhanced oxygen vacancy formation in the presence of halogens, ${ }^{39}$ thus decreasing the selectivity to $\mathrm{CH}_{3} \mathrm{X}$. In addition, $\mathrm{HX}$ atmosphere is detrimental for the stability of a great number of materials. Cu-based catalysts, inherited from Deacon process and widely applied in ethylene oxychlorination, ${ }^{40-41}$ were the first materials studied in MOC. Although exhibiting a noticeable productivity of chloromethane ( $Y=16 \%, S=85 \%)$, the instability of these catalysts limited their practical implementation. ${ }^{28} \mathrm{~A}$ continuous research to find an optimal oxyhalogenation catalyst led to the discovery of promising systems, comprising $\mathrm{LaOCl}$ for MOC, ${ }^{29} \mathrm{Ru}-$ and Rh-containing materials, ${ }^{30} \mathrm{TiO}_{2},{ }^{34} \mathrm{FePO}_{4},{ }^{32}$ and vanadyl pyrophosphate (VPO) $)^{34}$ for $\mathrm{MOB}$, and $\mathrm{CeO}_{2}$-based catalysts for both $\mathrm{MOC}$ and $\mathrm{MOB},{ }^{33}$ where the latter two materials provided the highest yields of $\mathrm{CH}_{3} \mathrm{Br}(Y=16 \%, S=64 \%)$ and $\mathrm{CH}_{3} \mathrm{Cl}$ $(Y=17 \%, S=74 \%$ ), respectively. Nevertheless, these studies were confined to a single type of $\mathrm{HX}$ and/or a single catalyst family, and were investigated in a relatively narrow kinetic regime. This not only limits the realistic comparison of the catalyst performance, but also hampers the understanding of the role of $\mathrm{HX}$ in oxyhalogenation chemistry.

Herein, we compared MOC and MOB over different catalyst families, characterized by diverse oxidizing properties, in a broad range of temperatures (600-873 K) and HX concentrations (015 vol.\%) to determine the dependence of product distribution on the nature of catalyst, and type of hydrogen halide and its partial pressure. These results were understood by the investigation of the related oxidation and gas-phase halogenation reactions, which also enabled to gain insights on the mechanism of methane oxyhalogenation. Finally, these findings were summarized vis-àvis for MOC and MOB in the form of extracted kinetics parameters, providing an overview of the oxyhalogenation performance of different materials as a function of HX. 


\section{EXPERIMENTAL}

2.1. Catalyst preparation. $\mathrm{RuO}_{2}$ was obtained by calcination of anhydrous $\mathrm{RuCl}_{3}$ (ABCR, 99.9\%) at $823 \mathrm{~K}$ in static air, while commercial $\mathrm{CeO}_{2}$ (Sigma-Aldrich, nanopowder, 99.9\%) and $\mathrm{TiO}_{2}$ (Sigma-Aldrich, rutile nanopowder, 99.5\%) were calcined at $1173 \mathrm{~K}$ and $873 \mathrm{~K}$, respectively, in static air prior to their use in the catalytic tests. (VO) ${ }_{2} \mathrm{P}_{2} \mathrm{O}_{7}$ (vanadyl pyrophosphate, VPO) was prepared by refluxing a suspension of $\mathrm{V}_{2} \mathrm{O}_{5}$ (Sigma-Aldrich, 99.5\%) in isobutanol (Acros Organics, 99\%) and benzyl alcohol (Sigma-Aldrich, 99\%) for $3 \mathrm{~h}$ with a molar $\mathrm{V}_{2} \mathrm{O}_{5}: \mathrm{C}_{4} \mathrm{H}_{10} \mathrm{O}: \mathrm{C}_{7} \mathrm{H}_{8} \mathrm{O}$ ratio of 1:12:6.5. After cooling down to room temperature, $\mathrm{H}_{3} \mathrm{PO}_{4}$ (Sigma-Aldrich, 85\%) was added to attain a molar P:V ratio of 1.2, and the mixture was then refluxed for another $16 \mathrm{~h}$. The resulting solid was recovered by filtration, washed with isobutanol and methanol (Fluka, 99.9\%), dried at $373 \mathrm{~K}$ in vacuum (50 mbar) for $12 \mathrm{~h}$, and thermally activated at $823 \mathrm{~K}$ in flowing $\mathrm{N}_{2}$. $\mathrm{FePO}_{4}$ was synthesized by mixing $\mathrm{Fe}\left(\mathrm{NO}_{3}\right)_{3} \cdot 9 \mathrm{H}_{2} \mathrm{O}$ (SigmaAldrich, 99\%) and $\mathrm{NH}_{4} \mathrm{H}_{2} \mathrm{PO}_{4}$ (Acros Organics, 99\%) in a molar P:Fe ratio of 1 in deionized water for $2 \mathrm{~h}$, followed by drying at $373 \mathrm{~K}$ in vacuum ( $50 \mathrm{mbar}$ ) for $12 \mathrm{~h}$ and calcination at $873 \mathrm{~K}$ in flowing air. The supported copper-based catalyst (Cu-K-La-X) containing 7 wt.\% Cu,

$2 \mathrm{wt} \% \mathrm{~K}$, and $2 \mathrm{wt} . \%$ La was prepared by sequential incipient wetness impregnation of precalcined (673 K in static air) $\gamma-\mathrm{Al}_{2} \mathrm{O}_{3}$ (Alfa Aesar, $160 \mathrm{~m}^{2} \mathrm{~g}^{-1}$ ) with an aqueous solution of $\mathrm{CuCl}_{2} \cdot 2 \mathrm{H}_{2} \mathrm{O}$ (Sigma-Aldrich, 99.99\%), $\mathrm{KCl}$ (Acros Organics, 99\%), and $\mathrm{LaCl}_{3} \cdot 7 \mathrm{H}_{2} \mathrm{O}$ (ABCR, 99.99\%), respectively. After each impregnation step, the impregnate was dried at $373 \mathrm{~K}$ in vacuum (50 mbar) for $12 \mathrm{~h}$. The thermal treatment for all catalysts was performed using a heating rate of $5 \mathrm{~K} \mathrm{~min}^{-1}$ and a holding time of $5 \mathrm{~h}$.

2.2. Characterization. Powder X-ray diffraction (XRD) was measured using a PANalytical X'Pert PRO-MPD diffractometer and $\mathrm{Cu}-\mathrm{K} \alpha$ radiation $(\lambda=0.154 \mathrm{~nm})$. The data was recorded in 
the $10-70^{\circ} 2 \theta$ range with an angular step size of $0.017^{\circ}$ and a counting time of $0.26 \mathrm{~s}$ per step. $\mathrm{N}_{2}$ sorption at $77 \mathrm{~K}$ was measured in a Quantachrome Quadrasorb-SI analyzer. Prior to the measurements, the samples were outgassed to 50 mbar at $573 \mathrm{~K}$ for $12 \mathrm{~h}$. The Brunauer-EmmettTeller (BET) method was applied to calculate the total surface area, $S_{\text {BET, }}$ in $\mathrm{m}^{2} \mathrm{~g}^{-1} \cdot{ }^{42} \mathrm{X}$-ray photoelectron spectroscopy (XPS) measurements were performed on a Physical Electronics Quantum 2000 X-ray photoelectron spectrometer using monochromatic Al-K $\alpha$ radiation generated from an electron beam operated at $15 \mathrm{kV}$, and equipped with a hemispherical capacitor electron-energy analyzer. The powdered sample were analyzed at the electron take-off angle of $45^{\circ}$ and the pass energy of $46.95 \mathrm{eV}$. Partial compensation of surface charging during spectra acquisition was obtained by the simultaneous operation of electron and argon ion neutralizers. Elemental concentrations are given in atomic percent using the measured photoelectron peak areas after Shirley background subtraction and the built-in sensitivity factors for calculation. Temperature-programmed reduction with hydrogen ( $\mathrm{H}_{2}$-TPR) was performed using a Micromeritics Autochem II 2920 unit equipped with a thermal conductivity detector coupled to a MKS Cirrus 2 mass spectrometer. The powder sample $\left(0.01 \mathrm{~g}\right.$ for $\mathrm{RuO}_{2}$ and $0.25 \mathrm{~g}$ for all other catalysts) was loaded into a U-shaped quartz micro-reactor, pretreated in He (20 $\mathrm{cm}^{3}$ STP $\left.\mathrm{min}^{-1}\right)$ at $673 \mathrm{~K}$ for $2 \mathrm{~h}$, and cooled to room temperature followed by ramping the temperature at $10 \mathrm{~K} \mathrm{~min}^{-1}$ up to $1273 \mathrm{~K}$ in 5 vol.\% $\mathrm{H}_{2}$ in $\mathrm{N}_{2}\left(20 \mathrm{~cm}^{3} \mathrm{STP} \mathrm{min}^{-1}\right)$.

2.3. Catalytic tests. All the catalytic tests were performed at ambient pressure in a continuousflow fixed-bed reactor set-up (Scheme 1). The quartz reactor (10 mm internal diameter) was loaded with a catalyst ( $W_{\text {cat }}=1.0 \mathrm{~g}$, particle size, $d_{\mathrm{p}}=0.4-0.6 \mathrm{~mm}$ ) diluted with quartz particles $\left(d_{\mathrm{p}}=0.2-0.3 \mathrm{~mm}\right)$ to ensure a constant bed volume $\left(V_{\text {bed }}=1.8 \mathrm{~cm}^{3}\right)$ and placed in a homemade electrical oven equipped with a K-type thermocouple placed in a coaxial quartz thermowell 
whose tip reaches the center of the catalyst bed. Prior to the tests, the catalyst was heated in a $\mathrm{He}$ flow till the desired bed temperature ( $T=423-895 \mathrm{~K}$ ), and then stabilized for 30 min under these conditions before the reaction mixture was admitted. Appropriate amounts of gases: $\mathrm{CH}_{4}$ (PanGas, purity 5.0), $\mathrm{HX}\left(\mathrm{X}=\mathrm{Cl}, \mathrm{Br}\right.$ ) (Air Liquide, purity 2.8, anhydrous), $\mathrm{O}_{2}$ (PanGas, purity 5.0), $\mathrm{CO}$ (Messer, 5 mol.\% in He 5.0), $\mathrm{Cl}_{2}$ (PanGas, purity 2.8), Ar (PanGas, purity 5.0) (internal standard), and He (PanGas, purity 5.0) (carrier gas) were fed by digital mass flow controllers (Bronkhorst ${ }^{\circledR}$ ) to achieve a desired feed composition at total volumetric flow, $F_{\mathrm{T}}$, of $6000 \mathrm{~cm}^{3} \mathrm{STP} \mathrm{h}^{-1}$ (space velocity, $F_{\mathrm{T}} / W_{\text {cat }}=6000 \mathrm{~cm}^{3} \mathrm{STP} \mathrm{h}^{-1} \mathrm{~g}^{-1}$ ). $\mathrm{CH}_{2} \mathrm{Cl}_{2}$ (Sigma-Aldrich, 99.5\%), $\mathrm{CH}_{2} \mathrm{Br}_{2}$ (ABCR, 99\%), and $\mathrm{Br}_{2}$ (Acros Organics, 99.6\%) were injected using a syringe pump (Nexus 6000, Chemyx) and subsequently vaporized in the carrier gas stream using a homebuilt vaporizer operated at $343 \mathrm{~K}$ accommodating a quartz $\mathrm{T}$-connector filled with glass (Scheme 1). The syringe was inserted in a jacket attached to a water-cooling system to maintain a constant temperature of the injected liquid. Reactions and feed compositions studied in this work are summarized in Table 1. Condensation of the reactants and products in the downstream lining was prevented by heating it at $393 \mathrm{~K}$. The effluent stream from the catalytic reactor was neutralized by passing it through an impinging bottle containing an aqueous $\mathrm{NaOH}$ solution (1 M).

Prior to the analysis of the reactor outlet gas stream, the reaction was stabilized under given conditions for at least $1 \mathrm{~h}$. The content of the carbon-containing compounds (i.e. $\mathrm{CH}_{4}$, $\mathrm{CH}_{3} \mathrm{Cl} / \mathrm{CH}_{3} \mathrm{Br}, \mathrm{CH}_{2} \mathrm{Cl}_{2} / \mathrm{CH}_{2} \mathrm{Br}_{2}, \mathrm{CHCl}_{3} / \mathrm{CHBr}_{3}$, $\mathrm{CO}$, and $\mathrm{CO}_{2}$ ), and $\mathrm{Ar}$ was determined on-line using a gas chromatograph equipped with a GS-Carbon PLOT column coupled to a mass spectrometer (GC-MS, Agilent GC 6890, Agilent MSD 5973N). $\mathrm{Cl}_{2}$ and $\mathrm{Br}_{2}$ were quantified by off-line iodometric titration (using a Mettler Toledo G20 Compact Titrator) of triiodide, formed 
by purging a stream containing a molecular halogen through an aqueous KI solution $(0.1 \mathrm{M})$, with $0.01 \mathrm{M}$ sodium thiosulfate solution (Sigma-Aldrich, 99.99\%). The content of $\mathrm{HBr}$ and $\mathrm{HCl}$ was determined from the same KI solution by an acid-base titration with $0.01 \mathrm{M} \mathrm{NaOH}$ solution (Sigma-Aldrich, 99.99\%), after neutralizing the formed triiodide with sodium thiosulfate. The conversion of the reactant $i, X(i)$ ( $i$ denotes $\mathrm{CH}_{4}, \mathrm{CH}_{2} \mathrm{Cl}_{2}, \mathrm{CH}_{2} \mathrm{Br}_{2}$, or $\mathrm{CO}$, as well as $\mathrm{HCl}$, and $\mathrm{HBr}$ in all the catalytic tests except $\mathrm{HX}$ oxidation) was calculated according to the following equation:

$$
X(i)=\frac{n(i)^{\text {inlet }}-n(i)^{\text {outlet }}}{n(i)^{\text {illet }}} \cdot 100, \%
$$

where $n(i)^{\text {inlet }}$ and $n(i)^{\text {outlet }}$ are the molar flows of the reactant $i$, at the inlet and outlet of the reactor, respectively, expressed in mol s${ }^{-1}$. The conversion of $\mathrm{HX}, X(\mathrm{HX})$, in the HX oxidation tests, was computed as:

$$
X(\mathrm{HX})=\frac{2 \cdot n\left(\mathrm{X}_{2}\right)^{\text {outlet }}}{n(\mathrm{HX})^{\text {inlet }}} \cdot 100, \%
$$

where $n\left(\mathrm{X}_{2}\right)^{\text {outlet }}$ and $n(\mathrm{HX})^{\text {inlet }}$ denote the molar flows of $\mathrm{X}_{2}$ and $\mathrm{HX}$ at the reactor outlet and inlet, respectively. Selectivity $S(j)$ and yield $Y(j)$ of product $j\left(j\right.$ denotes $\mathrm{CH}_{3} \mathrm{Cl}, \mathrm{CH}_{3} \mathrm{Br}_{2} \mathrm{CH}_{2} \mathrm{Cl}_{2}$, $\mathrm{CH}_{2} \mathrm{Br}_{2}, \mathrm{CHCl}_{3}, \mathrm{CO}$, or $\mathrm{CO}_{2}$ ) were determined according to the following equations:

$$
\begin{gathered}
S(j)=\frac{n(j)^{\text {outlet }}}{\sum_{\text {outlet }}^{\text {outlet }} n(j)^{\text {outlet }}} \cdot 100, \% \\
Y(j)=\frac{X(i) \cdot S(j)}{100}, \%
\end{gathered}
$$

where $n(j)^{\text {outlet }}$ is the molar flow of the species $j$ at the reactor outlet. 
The error of the carbon balance, $\varepsilon_{\mathrm{C}}$, was determined using the equation:

$$
\varepsilon_{\mathrm{C}}=\frac{n(i)^{\text {inlet }} \cdot N_{\mathrm{C}}(i)-\left(n(i)^{\text {outlet }} \cdot N_{\mathrm{C}}(i)+\sum n(j)^{\text {outlet }} \cdot N_{\mathrm{C}}(j)\right)}{n(i)^{\text {inlet }} \cdot N_{\mathrm{C}}(i)} \cdot 100, \%
$$

where $n(i)^{\text {inlet }}$ is the molar flow of reactant $i$ at the reactor inlet, $n(i)^{\text {outlet }}$ and $n(j)^{\text {outlet }}$ are molar flows of the reactant $i$ and product $j$ at the reactor outlet, respectively, while $N_{\mathrm{C}}(i)$ and $N_{\mathrm{C}}(j)$ are the number of carbon atoms in the reactant $i$ and product $j$, respectively. Likewise, the error of the halogen mass balance, $\varepsilon_{\mathrm{X}}$, was determined according to equation:

$$
\varepsilon_{\mathrm{X}}=\frac{\sum n(i)^{\text {inlet }} \cdot N_{\mathrm{X}}(i)-\left(\sum n(j)^{\text {outlet }} \cdot N_{\mathrm{X}}(j)+\sum n(i)^{\text {inlet }} \cdot N_{\mathrm{X}}(i)\right)}{\sum n(i)^{\text {inlet }} \cdot N_{\mathrm{X}}(i)} \cdot 100, \%
$$

where $n(i)^{\text {inlet }}$ denotes the molar flow of reactant $i$ at the reactor inlet, $n(i)^{\text {outlet }}$ and $n(j)^{\text {outlet }}$ are molar flows of the reactant $i$ and product $j$ (in addition to $\mathrm{CH}_{3} \mathrm{Cl}, \mathrm{CH}_{3} \mathrm{Br}, \mathrm{CH}_{2} \mathrm{Cl}_{2}, \mathrm{CH}_{2} \mathrm{Br}_{2}$, $\mathrm{CHCl}_{3}, j$ also denotes the molecular halogens $\mathrm{Cl}_{2}$ and $\mathrm{Br}_{2}$ ) at the reactor outlet, respectively, while $N_{\mathrm{X}}(i)$ and $N_{\mathrm{X}}(j)$ reffer to the number of halogen atom $\mathrm{X}$ in the corresponing compounds $i$ and $j$, respectively Each catalytic data point is determined as an average of at least two measurements. The carbon and halogen mass balance in all presented catalytic tests were closed at $95 \%$ or higher.

The reaction rate with respect to the reactant $i$ normalized per unit of weight of a catalyst, $r_{\mathrm{w}}(i)$, was determined as follows:

$$
r_{W}(i)=\frac{n(i)^{\text {inlet }}-n(i)^{\text {outlet }}}{W_{\text {cat }}}, \operatorname{mol}(i) \mathrm{s}^{-1} \mathrm{~g}_{\text {cat }}^{-1}
$$

while the reaction rate normalized per unit of surface area of a catalyst, $r_{\mathrm{s}}(i)$, was calculated according to the following equation: 


$$
r_{S}(i)=\frac{n(i)^{\text {inlet }}-n(i)^{\text {outlet }}}{W_{\text {cat }} S_{\text {BET }}}, \operatorname{mol}(i) \mathrm{s}^{-1} \mathrm{~m}_{\text {cat }}^{-2}
$$

In Eq. 7 and 8, $n(i)^{\text {inlet }}$ and $n(i)^{\text {outlet }}$ denote the molar flows of reactant $i$ at the reactor inlet and outlet, respectively, $W_{\text {cat }}$ denotes the weight of a catalyst in g, and $S_{\mathrm{BET}}$ is the surface area of the used catalyst in $\mathrm{m}^{2} \mathrm{~g}^{-1}$ determined by BET method.

After the tests, the catalyst bed was quenched to room temperature in He flow. The catalyst was separated by sieving from the quartz particles and collected for an ex situ characterization.

\section{RESULTS AND DISCUSSION}

3.1. Catalyst evaluation in methane oxyhalogenation. Methane oxychlorination and oxybromination were studied under variable temperature $(600-900 \mathrm{~K})$ and feed HX concentration (3-15 vol.\%) over different catalyst families, namely: $\mathrm{RuO}_{2}, \mathrm{Cu}-\mathrm{K}-\mathrm{La}-\mathrm{X}, \mathrm{CeO}_{2}$, VPO, $\mathrm{TiO}_{2}$, and $\mathrm{FePO}_{4}$, which were previously reported to be active in the oxyhalogenation of methane. ${ }^{28,32-34}$ The choice of these systems was based on their diverse oxidizing characters, as inferred from their $\mathrm{H}_{2}$-TPR profiles (Figure $\mathrm{S} 1$ ).

The comparison of the catalytic activity in MOB and MOC, as well as between different catalysts in the same reaction, can be achieved on different basis, generally involving the ranking of reaction rates, which can be expressed with respect to the surface area of a catalyst, its weight, or its volume, or classification based on the activation barriers. The advantages and disadvantages of the different approaches are discussed in more detail in the Supporting Information (Figure S2). Herein, catalytic activities are compared based on the relative position of the light-off curves of methane conversion versus temperature. These were obtained by performing the two reactions over a constant catalyst weight $(1 \mathrm{~g})$ and reaction volume $\left(1.8 \mathrm{~cm}^{3}\right)$, 
allowing the normalization of the reaction rate to catalyst weight and reaction volume. This widely accepted approach in catalysis, ${ }^{43}$ also applied in previous studies on oxyhalogenation, ${ }^{33-34}$ is found as particularly suitable, as it enables the comparison of the kinetics of different (partially) catalytic and non-catalytic reactions (vide infra), while still providing a differentiation of the single catalyst performance in two oxyhalogenation reactions, which are in the primary focus of our study. Based on this criteria, the overall activity ranking, $\mathrm{RuO}_{2}>\mathrm{Cu}-\mathrm{K}-\mathrm{La}-\mathrm{X}>$ $\mathrm{CeO}_{2}>\mathrm{VPO}>\mathrm{TiO}_{2}>\mathrm{FePO}_{4}$ (Figure 1, left column), is similar in two reactions. Still for $\mathrm{RuO}_{2}$ and $\mathrm{Cu}-\mathrm{K}-\mathrm{La}-\mathrm{X}$ catalysts, the light off curves are shifted to higher temperatures in MOB by ca. $100 \mathrm{~K}$ than in MOC, while they remained mostly identical for $\mathrm{CeO}_{2}$ and $\mathrm{VPO}$ and evidenced a reversed order over the least active $\mathrm{TiO}_{2}$ and $\mathrm{FePO}_{4}$ systems.

The product distribution patterns revealed that in general the selectivity to desired $\mathrm{CH}_{3} \mathrm{X}$ decreased, while that to $\mathrm{CO}_{x}$ increased with temperature. Despite being the most active catalyst, $\mathrm{RuO}_{2}$ led to a pronounced formation of $\mathrm{CO}_{2}$ in both $\mathrm{MOC}\left(S\left(\mathrm{CO}_{2}\right) \leq 77 \%\right)$ and $\mathrm{MOB}$ $\left(S\left(\mathrm{CO}_{2}\right) \leq 84 \%\right)$ over the all temperature range investigated. Likewise, although Cu-K-La-X

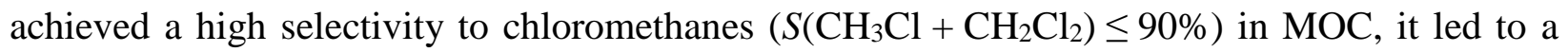
marked $\mathrm{CO}_{2}$ generation in $\mathrm{MOB}\left(S\left(\mathrm{CO}_{2}\right) \leq 60 \%\right)$. Besides, this catalyst suffered from severe metal leaching from the support in both reactions as observed in the form of the deposits on the reactor wall. These results are in line with previous studies on this material reporting the volatilization of copper phases in the oxychlorination of methane. ${ }^{28}$ Nevertheless, the performance of Cu-based catalysts is still presented here as an archetypical oxyhalogenation catalyst. The third most active catalyst, $\mathrm{CeO}_{2}$, led to the highest selectivity to chloromethanes (up to $90 \%)$, but displayed considerable $\mathrm{CO}_{2}$ formation in $\mathrm{MOB}\left(\mathrm{S}\left(\mathrm{CO}_{2}\right) \leq 50 \%\right)$, which makes it

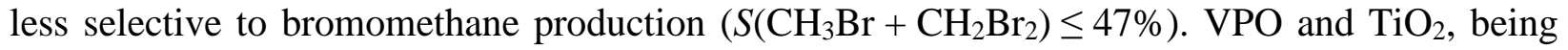


mildly oxidizing systems, provided selectivity to bromomethanes up to 84 and $75 \%$, respectively. However, in MOC, they both evidenced inferior selectivity to chloromethanes and instead showed a highly selective production of CO (S(CO) up to $96 \%$ and 90\%, respectively), which is still a valuable chemical intermediate. ${ }^{44} \mathrm{FePO}_{4}$, exhibited high selectivity to desired halomethanes in both MOC, in which it was investigated for the first time, and MOB (especially below $800 \mathrm{~K}$ ). Still, to achieve a reasonable conversion levels, this catalyst needs to be operated at high temperature, which compromises the $\mathrm{CH}_{3} \mathrm{X}$ production with $\mathrm{CO}$ formation. Overall, $\mathrm{CeO}_{2}$ is the most promising candidate for chloromethane formation, while VPO and $\mathrm{TiO}_{2}$ are suitable for bromomethane production.

The catalysts were further evaluated at variable HX concentrations (3-15 vol.\%) in order to investigate the impact of $\mathrm{HX}$ on their catalytic performance (Figure 2). $\mathrm{RuO}_{2}$ displayed a decrease in methane conversion with an increase in feed HX content in both MOC and MOB, whose effect was more pronounced in the latter reaction. In contrast, the activity of $\mathrm{FePO}_{4}$ was markedly promoted at higher concentrations of both $\mathrm{HCl}$ and $\mathrm{HBr}$. The promotion of activity was also observed over $\mathrm{Cu}-\mathrm{K}-\mathrm{La}-\mathrm{X}$ and $\mathrm{TiO}_{2}$ in $\mathrm{MOC}$, while in case of other materials, methane conversion was essentially unaffected by the variations in HX concentrations. More interestingly, the product distribution was significantly altered over $\mathrm{Cu}-\mathrm{K}-\mathrm{La}-\mathrm{X}, \mathrm{CeO}_{2}$, and $\mathrm{RuO}_{2}$ at higher inlet $\mathrm{HX}$ contents, especially when $\mathrm{HBr}$ was used. In particular, the selectivity to methyl bromide increased from 30,40 , and $25 \%$ to 50,80 , and $85 \%$, respectively, with corresponding drop in $\mathrm{CO}_{2}$ selectivity. On the other hand, this effect was less pronounced in MOC, especially over $\mathrm{CeO}_{2}$ showing almost no change in the selectivity to methyl chloride and a mild increase in selectivity to dichloromethane. Likewise, over $\mathrm{VPO}$ and $\mathrm{TiO}_{2}$, the selectivity to halomethanes was only slightly altered. 
All investigated materials were characterized by means of XRD and $\mathrm{N}_{2}$ sorption prior to (fresh) and after (used) the MOC and MOB tests. The diffractograms of the used samples evidenced no structural changes compared to their fresh analogues (Figure S3), thus testifying their robustness in oxyhalogenation conditions. The specific surface area of the sample after use in MOC or MOB was generally decreased compared to the fresh materials, which indicate a certain degree of sintering (Table S1). The only exception was the Cu-based catalyst, which showed a dramatic change in phase composition and significant increase in the surface area, indicating the volatilization of the deposited phase from the pores of the support.

3.2. Activity correlation with HX oxidation and gas-phase halogenation. To understand the performance differences among various catalyst families, the temperature at which $c a$. $15 \%$ conversion of methane is achieved, $T_{15}\left(\mathrm{CH}_{4}\right)$, is taken as a relative measure of their oxyhalogenation activity (Figure 3 ). The $T_{15}\left(\mathrm{CH}_{4}\right)$ values reflect the overall reactivity trends as derived by the light off curves (vide supra). Besides, $T_{15}\left(\mathrm{CH}_{4}\right)$ in MOC ranges from $630 \mathrm{~K}$ to $860 \mathrm{~K}$, whereas it falls in a narrower temperature range (690-780 K) in MOB. To shed light on these differences, we evaluated the performance of the catalysts in methane oxidation under comparable conditions to methane oxyhalogenation (Figure 4). Interestingly, the light-off curves in the former reaction were shifted to the higher temperatures compared to the corresponding profiles in methane oxyhalogenation (Figure 1), with $\mathrm{RuO}_{2}$ being the only exception. This result indicates the promotion of the methane conversion in the presence of HX, particularly over mild oxidants such as VPO and $\mathrm{TiO}_{2}$, which are scarcely able to activate methane unless a halogen source is present, and is in good agreement with the recent theoretical work of Metiu et al. who proposed the enhancement of $\mathrm{CH}_{4}$ activation on $\mathrm{CeO}_{2}$ surfaces in the presence of $\mathrm{HX}$ and $\mathrm{X}_{2}{ }^{45}$ 
To further elucidate the origin of the catalytic activity in the oxyhalogenation reactions, we have evaluated the representative materials in $\mathrm{HCl}$ and $\mathrm{HBr}$ oxidation (Figure 5). In line with previous studies, ${ }^{37}$ catalysts displayed $\mathrm{HCl}$ oxidation activity at higher temperatures compared to $\mathrm{HBr}$ oxidation. Interestingly, the catalyst rankings in $\mathrm{HX}$ oxidation coincided with those in methane oxyhalogenation, with $\mathrm{RuO}_{2}$ being the most active and $\mathrm{FePO}_{4}$ the least. Moreover, the $T_{15}\left(\mathrm{CH}_{4}\right)$ in methane oxyhalogenation correlates linearly with the $T_{15}(\mathrm{HX})$ in $\mathrm{HX}$ oxidation (Figure 6a), particularly in MOC, suggesting that the oxyhalogenation activity is controlled by the catalyst ability to activate HX. This correlation between the HX oxidation and oxyhalogenation activity is also observed if the catalysts activities are expressed on surface area basis (Figures S2, S4, S5). In case of $\mathrm{HCl}$, this behavior is not only limited to a selected methane or HX conversion level, but it is preserved over a wide temperature range. To demonstrate this, we determined the apparent activation energy for methane conversion in oxychlorination $\left(E_{a}\left(\mathrm{CH}_{4}\right)\right)$ (Figure S6, Table S2) and for $\mathrm{HCl}$ oxidation $\left(E_{a}(\mathrm{HX})\right)$. The strong linear dependence between these two parameters indicates that the correlation between the MOC and $\mathrm{HCl}$ oxidation is preserved in a broad temperature range (Figure 6b). Nevertheless, no dependence between the apparent activation energies of MOB and $\mathrm{HBr}$ oxidation was observed (Figure 6b).

These differences might be explained by considering the role of gas-phase methane halogenation in controlling the reactivity, as often proposed in the literature. ${ }^{31,34}$ Methane chlorination occurs at lower temperatures (ca. 573-673 K) than bromination (ca. 693-793 K). ${ }^{20,27}$ Thus, if the halogenation is controlling the overall reaction rate, the $\mathrm{X}_{2}$ evolved from the catalyst surface could only react when the temperature is sufficiently high for the homolytic C-H activation. Accordingly, we have studied the temperature dependence of the gas-phase methane halogenation (Figure 7) under equivalent conditions to methane oxyhalogenation. By extracting 
the $T_{15}\left(\mathrm{CH}_{4}\right)$ from the methane halogenation experiments, it can be observed that the distribution of $T_{15}\left(\mathrm{CH}_{4}\right)$ in both MOC and MOB falls in the region where the respective gas-phase halogenation is significant (Figure 6a). This supports the previous hypothesis that the oxyhalogenation reaction might proceed through a heterogeneous-gas-phase mechanism. At first glance, $\mathrm{MOB}$ over $\mathrm{RuO}_{2}$ might appear exceptional, as its $T_{15}\left(\mathrm{CH}_{4}\right)$ value in MOB is significantly lower compared to the corresponding one in the gas-phase bromination. Still, a high activity of this catalyst in $\mathrm{CH}_{4}$ oxidation (Figure 4), suggests that significant part of $\mathrm{CH}_{4}$ conversion in MOB might stem from its direct oxidation. This is further corroborated by the product distribution in MOB (Figure 1), wherein $\mathrm{RuO}_{2}$ leads to $\mathrm{CO}_{2}$ as a dominant product in the low temperature range (ca. $85 \%$ selectivity at $15 \% \mathrm{CH}_{4}$ conversion), while production of $\mathrm{CH}_{3} \mathrm{Br}$ starts to be significant only in the temperature window of the gas-phase bromination (Figure 7). In addition, a comparison of the catalyst activity in MOB and MOC unequivocally shows that although the bromine evolution is expected to be more facile than that of chlorine (Figure 5), $\mathrm{CH}_{3} \mathrm{Br}$ formation over $\mathrm{RuO}_{2}$ requires higher temperatures compared to $\mathrm{CH}_{3} \mathrm{Cl}$ production in congeneric oxychlorination (Figure 1). The same reasoning holds for $\mathrm{Cu}-\mathrm{La}-\mathrm{K}-\mathrm{X}$ and $\mathrm{CeO}_{2}$. The $T_{15}\left(\mathrm{CH}_{4}\right)$ values of these catalysts in oxybromination are much closer to the $T_{15}\left(\mathrm{CH}_{4}\right)$ in the bromination reaction, in line with their lower activity in $\mathrm{CH}_{4}$ oxidation compared to $\mathrm{RuO}_{2}$ (Figure 7). On the other hand, the $T_{15}\left(\mathrm{CH}_{4}\right)$ observed for $\mathrm{VPO}$, $\mathrm{TiO}_{2}$, and particularly $\mathrm{FePO}_{4}$ in MOC appear to be lower than the corresponding $T_{15}(\mathrm{HX})$, which might indicate a marked role of the catalyst in methane activation. To elucidate this important point, the rates of $\mathrm{CH}_{4}$ oxychlorination, $\mathrm{CH}_{4}$ oxidation, and $\mathrm{HCl}$ oxidation are compared in the broader temperature window (Figure 9, vide infra, Figure S8). From this representation it can be observed that (i) methane oxidation over $\mathrm{TiO}_{2}$ and particularly VPO proceeds at significantly higher temperatures 
compared to MOC, suggesting the low propensity of these two catalysts to activate methane in a temperature window of the oxychlorination reaction; (ii) the rate of MOC over VPO and $\mathrm{TiO}_{2}$ is generally comparable to the rate of $\mathrm{HCl}$ oxidation, particularly at lower conversion levels. Besides, both VPO and $\mathrm{TiO}_{2}$ favor $\mathrm{CO}$ production (Figure 1), whereby $\mathrm{HCl}$ is continuously regenerated along the catalyst bed. This suggests a higher effective concentration of this reactant in oxychlorination compared to sole $\mathrm{HCl}$ oxidation, which might contribute to the slightly higher rate of the former with respect to the latter reaction. In contrast, the activity of $\mathrm{FePO}_{4}$ in $\mathrm{MOC}$ and $\mathrm{CH}_{4}$ oxidation is significantly higher than that in $\mathrm{HCl}$ oxidation, indicating a low chlorine evolution under oxychlorination conditions. Moreover, this catalyst requires the highest operating temperature in MOC. Based on these considerations, a gradual transition from mostly gas-phase to the heterogeneous $\mathrm{C}-\mathrm{Cl}$ bond formation when going from $\mathrm{VPO}$ to $\mathrm{FePO}_{4}$ can be proposed.

It is interesting to note that by switching halogen source from $\mathrm{HCl}$ to $\mathrm{HBr}$ the variance of the distribution of the $T_{15}\left(\mathrm{CH}_{4}\right)$ reduces significantly (Figure 6a) between the two reactions. This difference might originate from a change in the rate determining step (r.d.s.) of the reaction. In essence, the reaction rate in MOC could be primarily determined by the evolution of $\mathrm{Cl}_{2}$ from the catalyst surface, which is proved to be the most energy demanding step in Deacon reaction. ${ }^{36,46-48}$ This not only rationalizes the strong correlation between $T_{15}\left(\mathrm{CH}_{4}\right)$ and $T_{15}(\mathrm{HCl})$ (Figure 6a), but also explains why this is preserved over a wide temperature range (Figure 6b). On the contrary, in MOB the r.d.s. might be the reaction between the evolved $\mathrm{Br}_{2}$ with $\mathrm{CH}_{4}$ in the gas-phase. This can describe (i) the decrease in activity in MOB of the highly active $\mathrm{HBr}$ oxidation catalysts, such as $\mathrm{RuO}_{2}$ and $\mathrm{CeO}_{2}$ compared to the respective $\mathrm{HCl}$-driven reactions, (ii) the narrow distribution of the $T_{15}\left(\mathrm{CH}_{4}\right)$ in $\mathrm{MOB}$, centered in the region of $T_{15}\left(\mathrm{CH}_{4}\right)$ for gas-phase 
bromination observed for all catalysts, except for $\mathrm{RuO}_{2}$, and (iii) the absence of correlation between $E_{\mathrm{a}}\left(\mathrm{CH}_{4}\right)$ and $E_{a}(\mathrm{HBr})$.

3.3. Rationalization of selectivity patterns in oxyhalogenation. Product selectivity is another important aspect of the oxyhalogenation performance, which for a given catalyst depends on reactor geometry, space-velocity, feed-composition, degree of conversion, and reaction temperature. ${ }^{43}$ These however cannot all be fixed simultaneously, since conversion is also a function of the remaining parameters. Herein, we fixed all the parameters except the temperature, which was varied so to achieve the constant level of methane conversion of $c a$. $15 \%$ at which selectivity to halomethanes $\left(\mathrm{CH}_{3} \mathrm{X}, \mathrm{CH}_{2} \mathrm{X}_{2}\right)$, $\mathrm{CO}$, and $\mathrm{CO}_{2}$ in $\mathrm{MOC}$ and $\mathrm{MOB}$ were compared (Figure 8). $\mathrm{RuO}_{2}$ led to a pronounced $\mathrm{CO}_{2}$ formation in both $\mathrm{MOB}$ and $\mathrm{MOC}$, in line with its highest reducibility as evident from its $\mathrm{H}_{2}$-TPR profile (Figure S1). However, it is interesting to note that in contrast to the other catalysts, the selectivity to $\mathrm{CH}_{3} \mathrm{Br}$ in $\mathrm{MOB}$ over $\mathrm{RuO}_{2}$ was enhanced at higher temperatures (Figure 1). This apparently contradictory result might be explained by the high activity of $\mathrm{RuO}_{2}$ in $\mathrm{CH}_{4}$ (Figure 4) and $\mathrm{HBr}$ (Figure 5) oxidation, generally proceeding at temperatures which are substantially lower compared to MOB. Based on this, $\mathrm{CO}_{2}$ and $\mathrm{Br}_{2}$ are the principal reaction products (along with water) in the lower temperature regime of $\mathrm{MOB}$, while $\mathrm{O}_{2}$ consumption is almost quantitative, in good agreement with our experimental observations. At higher temperatures, the generated $\mathrm{Br}_{2}$ reacts with $\mathrm{CH}_{4}$, increasing thus the yield of $\mathrm{CH}_{3} \mathrm{Br}$, while the yield of $\mathrm{CO}_{2}$ is almost constant (Figure S9), ultimately resulting in an increased selectivity towards $\mathrm{CH}_{3} \mathrm{Br}$. Nevertheless, the inevitable $\mathrm{CO}_{2}$ formation caused by the marked propensity of this catalyst to combust methane as well as bromocompounds hampers the achievement of $100 \%$ selectivity to $\mathrm{CH}_{3} \mathrm{Br}$ (Figure 1). 
On the other hand, $\mathrm{Cu}-\mathrm{K}-\mathrm{La}-\mathrm{X}$ and $\mathrm{CeO}_{2}$ were more selective to $\mathrm{CH}_{3} \mathrm{X}$ in $\mathrm{MOC}$ than in $\mathrm{MOB}$ due to the pronounced over-oxidation to $\mathrm{CO}_{2}$ in the latter reaction. In contrast, $\mathrm{TiO}_{2}$ and $\mathrm{VPO}$ attained high selectivity to $\mathrm{CH}_{3} \mathrm{X}$ in MOB while resulted in the production of $\mathrm{CO}$ in MOC. Interestingly, $\mathrm{FePO}_{4}$ catalyst exhibited a high selectivity to $\mathrm{CH}_{3} \mathrm{X}$ in both $\mathrm{MOC}$ and $\mathrm{MOB}$.

To rationalize the observed selectivity patterns, the rate of methane oxyhalogenation was compared with that of methane, $\mathrm{HX}$, and $\mathrm{CH}_{2} \mathrm{X}_{2}$ oxidation over the representative catalysts, $\mathrm{CeO}_{2}$, VPO, and $\mathrm{FePO}_{4}$, showing three different product distribution trends (Figure 9). In case of $\mathrm{CeO}_{2}$, the rate of $\mathrm{HX}$ oxidation is significantly higher compared to the rate of MOC, which is greater than the rate of $\mathrm{CH}_{2} \mathrm{Cl}_{2}$ and methane oxidation. From this activity order, it follows that in MOC over $\mathrm{CeO}_{2}$ the chloromethanes are formed at higher rate than they are consumed in the corresponding oxidation reactions, in good agreement with the relatively high selectivity to these products. Moreover, since $\mathrm{HX}$ oxidation is significantly faster than $\mathrm{CH}_{2} \mathrm{Cl}_{2}$ oxidation, it may reduce the concentration of $\mathrm{O}_{2}$ in the system, which can additionally suppress the oxidation of chloromethanes. The analogous explanation also holds for the high selectivity to bromomethanes in MOB over VPO and $\mathrm{FePO}_{4}$, since the rate of $\mathrm{HBr}$ oxidation is significantly higher than the rate of $\mathrm{MOB}$, which is almost comparable to the rate of $\mathrm{CH}_{2} \mathrm{Br}_{2}$ oxidation. On the other hand, the rate of $\mathrm{MOB}$ over $\mathrm{CeO}_{2}$ is significantly lower than the rate of $\mathrm{CH}_{2} \mathrm{Br}_{2}$ oxidation, suggesting that bromomethanes once produced readily undergo oxidation, thus resulting in a limited selectivity to these products. Nevertheless, the rate of $\mathrm{HBr}$ oxidation is still higher than the rate of $\mathrm{CH}_{2} \mathrm{Br}_{2}$ oxidation indicating that competition between these two reactions might be exploited to suppress the $\mathrm{CO}_{x}$ formation (Figure 2, vide infra). In case of VPO, the kinetics of $\mathrm{HCl}$ oxidation is comparable to that of $\mathrm{CH}_{2} \mathrm{Cl}_{2}$ oxidation in the low reaction rate regime, while $\mathrm{CH}_{2} \mathrm{Cl}_{2}$ oxidation is slightly faster than the rate of oxychlorination, which might explain the low selectivity to this 
product, and a high selectivity to CO. As already discussed in the Section 3.2, $\mathrm{FePO}_{4}$ exhibits somewhat exceptional performance in MOC compared to the other catalysts, since the rate of $\mathrm{HCl}$ oxidation is significantly lower compared to rate of MOC, suggesting that the latter reaction over this catalyst likely involves surface participation in activating methane. Similar to MOB, the rate of $\mathrm{CH}_{2} \mathrm{Cl}_{2}$ oxidation is comparable, or lower than the rate of MOC, in line with the low $\mathrm{CO}_{x}$ evolution over this catalyst.

These contrasting behaviors of the catalysts in two reactions are further assessed by considering the impact of $\mathrm{HX}$ on the product distribution and the catalyst activity. For this purpose, the partial reaction orders for $\mathrm{CH}_{4}$ conversion $\left(n\left(\mathrm{CH}_{4}\right)\right)$, and for $\mathrm{CO}(n(\mathrm{CO}))$ and $\mathrm{CO}_{2}$ $\left(n\left(\mathrm{CO}_{2}\right)\right)$ production with respect to the variation of feed $\mathrm{HX}$ concentration were determined (Figure 10, Figure S6, Figure S7, and Table S2). The positive, zero, or negative values of these parameters express a positive, null, or negative effect, respectively, on $\mathrm{CH}_{4}$ conversion and $\mathrm{CO}_{x}$ formation. Considering first the role of feed $\mathrm{HX}$ content on the activity, $\mathrm{RuO}_{2}$ appears to be adversely affected in both reactions, with $n\left(\mathrm{CH}_{4}\right)=-0.67$ in $\mathrm{MOC}$ and -0.90 in $\mathrm{MOB}$. Higher deactivation in case of MOB than MOC is in line with the more vigorous surface halogenation by $\mathrm{HBr}$ compared to $\mathrm{HCl}$, which might lead to subsurface bromination forming inactive bromide phases, as recently found in congeneric $\mathrm{HX}$ oxidation. ${ }^{49-50} \mathrm{Cu}-\mathrm{La}-\mathrm{K}-\mathrm{X}$ and $\mathrm{CeO}_{2}$ exhibited slightly negative $n\left(\mathrm{CH}_{4}\right)$ in MOB, while they showed activity promotion, particularly in case of Cu-La-K-X, in MOC. More interestingly, VPO, $\mathrm{TiO}_{2}$, and $\mathrm{FePO}_{4}$, displayed positive values of $n\left(\mathrm{CH}_{4}\right)$ at higher $\mathrm{HX}$ content, with $\mathrm{FePO}_{4}$ showing the highest promotion effect, in both MOC and MOB.

Secondly, considering the suppression of $\mathrm{CO}_{x}$, the $\mathrm{CO}$ formation in $\mathrm{MOC}$ is essentially unaltered by the variation of the inlet $\mathrm{HCl}$ content, except over $\mathrm{FePO}_{4}$ and the $\mathrm{Cu}-\mathrm{K}-\mathrm{La}-\mathrm{X}$, which 
displayed positive $n(\mathrm{CO})$ of 0.43 and 0.81 , respectively. A marked suppression of $\mathrm{CO}_{x}$ formation upon increasing the content of $\mathrm{HX}$ in the feed was observed over $\mathrm{RuO}_{2}$ (Figure 2). This effect was particularly pronounced in $\mathrm{MOB}$, which hints that an operation of this catalyst under high $\mathrm{HBr}$ concentration at high temperatures might compensate the inhibition effect of $\mathrm{HBr}$ on the methane conversion, while preserving a high selectivity to bromomethanes. Nevertheless, an excursion to the higher temperature enhances the combustion despite the high $\mathrm{HBr}$ concentration, and promotes the formation of $\mathrm{CH}_{2} \mathrm{Br}_{2}$ at the expenses of $\mathrm{CH}_{3} \mathrm{Br}$ (Figure S10). In $\mathrm{MOB}, \mathrm{CeO}_{2}$ showed the strong promotion in $\mathrm{CO}$ formation when exposed to an increased $\mathrm{HBr}$ concentration, whereas the opposite behavior was observed over VPO $(n(\mathrm{CO})=-0.45)$ and $\mathrm{TiO}_{2}$ $(n(\mathrm{CO})=-0.2)$. High $\mathrm{HX}$ content brought to a reduction in the formation of $\mathrm{CO}_{2}$ over $\mathrm{CeO}_{2}$. Herein, a switch from stoichiometric 6 to 15 vol.\% HX led to a marked increase in productivity of chloromethanes (from $\sim 23 \%$ yield at $73 \%$ total selectivity to $\sim 27 \%$ total yield at $82 \%$ selectivity) and bromomethanes (from 11\% total yield at 57\% selectivity to $20 \%$ total yield at 98\% selectivity), respectively, at unaltered methane conversion. To the best of our knowledge, these are the highest values reported in literature to date. ${ }^{29-34}$ In case of $\mathrm{MOB}$ over $\mathrm{CeO}_{2}$, only trace amounts of oxygen were detected at the reactor outlet when $\mathrm{HBr}$ content was increased from 6 vol.\% to 15 vol.\%, while the conversion of $\mathrm{HBr}$ formally decreased from $90 \%$ (6 vol.\% $\mathrm{HBr})$ to $75 \%(15 \mathrm{vol} . \% \mathrm{HBr})$. The latter value is close to the theoretical maximum of $80 \%$ calculated from the stoichiometry of $\mathrm{HBr}$ oxidation. These results imply that the suppression of $\mathrm{CO}_{x}$ formation might come from the significantly faster kinetics of $\mathrm{HBr}$ oxidation compared to the bromomethane oxidation (Figure 9), which leads to a fast depletion of oxygen in the system. Moreover, an excess of $\mathrm{HBr}$ might favor the bromination of $\mathrm{CeO}_{2}$, thus lessening its reducibility. 
To elucidate these effects, $\mathrm{CeO}_{2}$ used in $\mathrm{MOB}$ as well as in MOC, was characterized in more detail.

The XRD analysis of the samples after testing under low (6 vol.\%) and high (15 vol.\%) HX contents revealed no alterations of bulk structure compared to its fresh analogue (Figure S3, S11a), discarding any role of bulk on selectivity reforms. Thus, the used $\mathrm{CeO}_{2}$ was analyzed by means of XPS (Figure S11b, c, and Table 2), which demonstrated that the Cl:Ce ratios in the surface region after exposure to 6 vol.\% (MOC-6) and 15 vol.\% HCl (MOC-15) were essentially identical, in good agreement with the less pronounced improvement of chloromethane selectivity at high $\mathrm{HCl}$ content (vide supra). On the contrary, an exposure to 15 vol.\% $\mathrm{HBr}$ (MOB-15) was necessary to achieve comparable surface Br:Ce ratios, correlating well with the significant increase in the selectivity to bromocarbons observed under these conditions (vide supra). A lower Br:Ce compared to $\mathrm{Cl}$ :Ce under stoichiometric feed composition indicates that the bromine evolution from the catalyst surface is more facile compared to that of chlorine under oxyhalogenation conditions (> $733 \mathrm{~K}$ (Figure 5) ), in line with the HX oxidation studies reported previously. ${ }^{37,49-50}$

To further substantiate the suppression of the combustion reactions upon HX addition, we have studied the oxidation of $\mathrm{CH}_{2} \mathrm{X}_{2}$ and $\mathrm{CO}$ in the presence (6 vol.\%) or absence of $\mathrm{HX}$ over $\mathrm{CeO}_{2}$. The impact of halogen co-adsorption is evidenced in $\mathrm{CH}_{2} \mathrm{Cl}_{2}$ oxidation (Figure 11a), which generally yielded $\mathrm{CO}$ and $\mathrm{CO}_{2}$ as main products with traces of $\mathrm{CHCl}_{3}$. An addition of $\mathrm{HCl}$ to the feed brought to a significant suppression of $\mathrm{CO}_{2}$ formation and a redirection of the reaction towards the formation of $\mathrm{CHCl}_{3}$, especially at lower temperatures. Nevertheless, the impact of $\mathrm{HCl}$ was gradually descending at higher temperatures till the cease of $\mathrm{CHCl}_{3}$ formation, which might be related to the evolution of the protective surface halogen coverage, as being 
demonstrated in congeneric $\mathrm{HCl}$ oxidation. ${ }^{46}$ However, the formation of $\mathrm{CO}_{2}$ was still suppressed under these conditions $\left(S\left(\mathrm{CO}_{2}\right) \leq 20 \%\right)$. This is further corroborated by the great inhibitory effect of $\mathrm{HCl}$ on the oxidation of $\mathrm{CO}$ (Figure 11b), also in accordance to previous studies in Deacon chemistry. ${ }^{51}$ In case of $\mathrm{CH}_{2} \mathrm{Br}_{2}$ oxidation, the addition of $\mathrm{HBr}$ led to the significant increase of the light-off temperature (Figure S12), which is in a good agreement with the strongly suppressed combustion at high $\mathrm{HBr}$ contents. In contrast to $\mathrm{CH}_{2} \mathrm{Cl}_{2}$ oxidation, no polybrominated products could be observed. The conversion of $\mathrm{HBr}$ under these conditions was $>99 \%$, suggesting that suppression of oxidation might partially arise from the competition of the two reactions for the available oxygen in the feed. Nevertheless, the concentration of $\mathrm{O}_{2}$ remains high even after full $\mathrm{HBr}$ conversion, as inferred from $\mathrm{ca} .60 \% \mathrm{CH}_{2} \mathrm{Br}_{2}$ conversion observed at the highest temperature applied $(660 \mathrm{~K})$ in the co-feeding test (Figure S12). Hence, fourfold decrease in $\mathrm{CH}_{2} \mathrm{Br}_{2}$ conversion (from $80 \%$ in the absence of $\mathrm{HBr}$ to $19 \%$ at 6 vol.\% $\mathrm{HBr}$ ) at $c a$. $620 \mathrm{~K}$ indicates that the inhibition effect of $\mathrm{HBr}$ on the $\mathrm{CH}_{2} \mathrm{Br}_{2}$ oxidation activity is primarily caused by the decrease of the catalyst’s reducibility.

As it is previously discussed, a drop in the selectivity to halocarbons when increasing the methane conversion at higher temperatures was a common feature for all the catalysts, except $\mathrm{RuO}_{2}$ in MOB. The decrease in the selectivity might be caused by the additional enhancement of the combustion reactions at increased temperature, which was used here to promote the methane conversion. To examine this effect, the product distribution in the oxyhalogenation was compared at constant conversion level that was adjusted by varying both the temperature and space-velocity $\left(F_{\mathrm{T}} / W_{\text {cat }}\right)$. As exemplified over $\mathrm{CeO}_{2}$ (Figure $\mathrm{S} 13$ ), a low space-velocity favors the oxidation of methane and halocarbons despite the lower temperatures. These results suggest that high temperature itself is not detrimental for the selectivity to halocarbons. 


\subsection{Overview of the catalytic potential in methane oxyhalogenation. To systematically}

analyze the complex oxyhalogenation chemistry, which involves multivariable dependence and multi-objective performance classification, kinetics parameters were extracted from the above discussion and presented in an integrated manner for MOC and MOB (Figure 12a, b). The upper half of the radar charts classifies materials based on their activity and tendency towards over oxidation. Thus, the systems exhibiting high activity (low $T_{15}$, high $E_{a}\left(\mathrm{CH}_{4}\right)$ ) for methane conversion, which is even promoted by the $\mathrm{HX}$ addition $\left(n\left(\mathrm{CH}_{4}\right)>0\right)$, and low propensity to $\mathrm{CO}_{2}$ formation (low $\left.S\left(\mathrm{CO}_{2}\right), n\left(\mathrm{CO}_{2}\right)<0\right)$ approach the periphery of the plot and are regarded as good oxyhalogenation catalysts. Given the complexity of the oxyhalogenation process, the activation barriers extracted from the temperature variation experiments likely lump the contributions from the different heterogeneous and/or homogenous reaction steps that might vary among various oxyhalogenation catalysts. Since the determined activation barriers do not necessarily reflect the intrinsic catalyst propensity to facilitate the halomethane formation, these are not used as criteria for ranking their performance. Instead, the activity of the catalysts is primarily related to the temperature window of their operation, here presented by $T_{15}\left(\mathrm{CH}_{4}\right)$, while the apparent activation energy is considered as a kinetic parameter reflecting the increment in the reaction rate upon a change in temperature. Since higher values of the latter parameter indicate a steeper increase in reaction rate with temperature, they are perceived as advantageous. In this respect, $\mathrm{RuO}_{2}$ that suffers from $\mathrm{HX}$ poisoning and shows high $\mathrm{CO}_{2}$ production in both $\mathrm{MOC}$ and $\mathrm{MOB}$, can be considered as suboptimal catalyst since its coordinates approach the center in both radar plots. On the other hand, $\mathrm{CeO}_{2}$ and particularly $\mathrm{Cu}-\mathrm{K}-\mathrm{La}-\mathrm{X}$ showed opposite trend in MOC and MOB, as their calculated parameters lie in the outer annulus for the former reaction and in the inner part for the latter case. Although the results in MOC might appear promising, the instability of the Cu- 
based catalyst makes it unattractive for potential industrial application. Mild oxidants, such as $\mathrm{TiO}_{2}, \mathrm{FePO}_{4}$, and $\mathrm{VPO}$, placing themselves towards outer edge of the plot in the oxybromination reaction, are more effective in MOB than MOC. Besides, their activity is promoted at increased $\mathrm{HBr}$ content.

This analysis is further expanded at the bottom half of the radar plots, that classifies materials based on their ability to produce the desired $\mathrm{CH}_{3} \mathrm{X}$ (high $S\left(\mathrm{CH}_{3} \mathrm{X}\right.$ ), low $S(\mathrm{CO}), n(\mathrm{CO})<0$ ) if they lie on the outer annulus of the plot. Thus, it can be seen that $\mathrm{CeO}_{2}$ and $\mathrm{FePO}_{4}$ are centrifugally displayed in the bottom part of the MOC radar, since they act as the most effective $\mathrm{CH}_{3} \mathrm{Cl}$ producers, both reaching a $\mathrm{S}\left(\mathrm{CH}_{3} \mathrm{Cl}\right)$ of $75 \%$, and display positive sensitivity to $\mathrm{HCl}$. Still, $\mathrm{CeO}_{2}$ offers advantage of lower operating temperature over $\mathrm{FePO}_{4}$.

The same pattern obtained in the catalyst classification from the top part of the radars is also observed in the bottom section, with less reducible catalysts being more effective $\mathrm{CH}_{3} \mathrm{Br}$ producers. In particular, VPO and $\mathrm{FePO}_{4}$ showed the highest $\mathrm{S}\left(\mathrm{CH}_{3} \mathrm{Br}\right)$, which can be increased at higher $\mathrm{HBr}$ contents $(n(\mathrm{CO})<0)$. This exceptional performance makes them effective MOB catalysts.

VPO and $\mathrm{TiO}_{2}$, displayed in the center of the bottom MOC radar, exhibit the unique possibility to selectively produce $\mathrm{CO}(\mathrm{S}(\mathrm{CO})=95$ and $78 \%)$ via oxychlorination chemistry that could not be obtained over any other investigated material and under any conditions when $\mathrm{HBr}$ was used as halogenating agent, which point to the complexity of oxyhalogenation chemistry, dependent not only on the nature of the catalyst but also on the type of $\mathrm{HX}$ and operating conditions. 


\section{CONCLUSIONS}

In this study, analogies and differences between MOC and MOB were assessed through the steady-state catalytic evaluation of different materials under variable conditions coupled to selected characterization techniques. Based on these, the relationships between the oxyhalogenation, gas-phase halogenation, hydrogen halide and methane oxidation were established for the first time over diverse set of materials, suggesting that the activity in the oxyhalogenation reaction depends on (i) the ability of a catalyst to oxidize HX, and (ii) the inherent propensity of the thus produced molecular halogen to react with methane in the gasphase. The performance of $\mathrm{FePO}_{4}$ was somewhat exceptional to this rule, as its MOC activity substantially exceeds that in $\mathrm{HCl}$ oxidation, which might suggest the active participation of the catalytic surface in $\mathrm{C}-\mathrm{Cl}$ bond formation. In terms of product distribution, it was found to be dependent not only on the nature of the catalyst, but also on the type of HX, as well as its partial

pressure. Thereby, four different classes of catalysts were observed: (i) $\mathrm{RuO}_{2}$ favoring combustion in both $\mathrm{MOC}$ and $\mathrm{MOB}$, (ii) $\mathrm{CeO}_{2}$ and $\mathrm{Cu}-\mathrm{K}-\mathrm{La}-\mathrm{X}$ which are effective chloromethanes producers, while in MOB they lead to $\mathrm{CO}_{2}$ formation, (iii) $\mathrm{VPO}$ and $\mathrm{TiO}_{2}$ that are selective to bromomethanes, but in MOC they bring to selective CO formation, and (iv) $\mathrm{FePO}_{4}$ showing a high selectivity to halomethanes in both MOB and MOC. These selectivity patterns are explained by the differences in reaction rates between the oxyhaloganetion, $\mathrm{CH}_{2} \mathrm{X}_{2}$ oxidation, and HX oxidation. A high selectivity to halomethanes is achieved if the rate of oxyhalogenation is greater than, or comparable to the rate of $\mathrm{CH}_{2} \mathrm{X}_{2}$ oxidation, while the rate of $\mathrm{HX}$ oxidation should be higher than the rate of $\mathrm{CH}_{2} \mathrm{X}_{2}$ oxidation. Regarding the impact of $\mathrm{HX}$ concentration on the product distribution, it is here shown that the selectivity to halocarbons over the first and second class of catalysts can be boosted if these are operated under high HX 
concentration. This enhancement was especially pronounced over $\mathrm{CeO}_{2}$, resulting in the highest reported yields of chloro- and bromocarbons (ca. 27\% and 20\%, respectively), which might be related to the (i) faster kinetics of the HX oxidation step compared to halocarbon combustion, and (ii) an enhanced reduction of the surface of the catalyst.

These experimental findings shed light on great diversity of the oxyhalogenation chemistry. Nevertheless, a comprehensive understanding of the phenomena presented here should be related to the intrinsic properties of the materials, which is essential for the rational catalyst design and necessitates the application of advanced operando characterization techniques and theoretical modeling, which should be undertaken in future studies.

\section{ASSOCIATED CONTENT}

Supporting Information. Supplementary information associated with this article, containing additional catalytic and characterization data, can be found in the online version.

\section{AUTHOR INFORMATION}

\section{Corresponding Author}

*Address: Institute for Chemical and Bioengineering, Department of Chemistry and Applied Biosciences, ETH Zurich, Vladimir-Prelog-Weg 1, CH-8093, Zurich, Switzerland. Phone: +41 44633 7120. E-mail: jpr@chem.ethz.ch.

\section{Author Contributions}

${ }^{\dagger}$ These authors contributed equally to this work. The manuscript was written through contributions of all authors. All authors have given approval to the final version of the manuscript. 


\section{ACKNOWLEDGMENTS}

This work was supported by the Swiss National Science Foundation (project no. 200021156107) and by ETH Zurich (research grant ETH-04 16-1). The authors thank Dr. Roland Hauert for the XPS measurements and Nicolas Aellen for assistance with catalyst testing.

\section{REFERENCES}

(1) Horn, R.; Schlögl, R. Catal. Lett. 2015, 145, 23-39.

(2) McFarland, E. Science 2012, 338, 340-342.

(3) Lunsford, J. H. Catal. Today 2000, 63, 165-174.

(4) Rostrup-Nielsen, J. R. In Handbook of Heterogeneous Catalysis; Wiley-VCH: Weinheim, 2008; Vol. 13.11, p 2882.

(5) Labinger, J. A.; Bercaw, J. E. Nature 2002, 417, 507-514.

(6) Tollefson, J. Nature, doi:10.1038/nature.2016.19141.

(7) Khalilpour, R.; Karimi, I. A. Energy 2012, 40, 317-328.

(8) U.S. Energy Information Administration Monthly Energy Review June; Washington, U.S., 2016.

(9) Enger, B. C.; Lødeng, R.; Holmen, A. Appl. Catal., A 2008, 346, 1-27.

(10) Zavyalova, U.; Holena, M.; Schlögl, R.; Baerns, M. ChemCatChem 2011, 3, 19351947.

(11) Beck, B.; Fleischer, V.; Arndt, S.; Hevia, M. G.; Urakawa, A.; Hugo, P.; Schomäcker, R. Catal. Today 2014, 228, 212-218. 
(12) Guo, X. G.; Fang, G. Z.; Li, G.; Ma, H.; Fan, H. J.; Yu, L.; Ma, C.; Wu, X.; Deng, D. H.; Wei, M. M.; Tan, D. L.; Si, R.; Zhang, S.; Li, J. Q.; Sun, L. T.; Tang, Z. C.; Pan, X. L.; Bao, X. H. Science 2014, 344, 616-619.

(13) Spivey, J. J.; Hutchings, G. Chem. Soc. Rev. 2014, 43, 792-803.

(14) Beznis, N. V.; van Laak, A. N. C.; Weckhuysen, B. M.; Bitter, J. H. Microporous Mesoporous Mater. 2011, 138, 176-183.

(15) Starokon, E. V.; Parfenov, M. V.; Pirutko, L. V.; Abornev, S. I.; Panov, G. I. J. Phys. Chem. C 2011, 115, 2155-2161.

(16) Grundner, S.; Markovits, M. A. C.; Li, G.; Tromp, M.; Pidko, E. A.; Hensen, E. J. M.; Jentys, A.; Sanchez-Sanchez, M.; Lercher, J. A. Nat. Commun. 2015, 6, 7546.

(17) Tomkins, P.; Mansouri, A.; Bozbag, S. E.; Krumeich, F.; Park, M. B.; Alayon, E. M.; Ranocchiari, M.; van Bokhoven, J. A. Angew. Chem. Int. Ed. 2016, 55, 5467-5471.

(18) Olah, G. A.; Gupta, B.; Farina, M.; Felberg, J. D.; Ip, W. M.; Husain, A.; Karpeles, R.; Lammertsma, K.; Melhotra, A. K.; Trivedi, N. J. J. Am. Chem. Soc. 1985, 107, 70977105.

(19) Olah, G. A. Acc. Chem. Res. 1987, 20, 422-428.

(20) Bucsi, I.; Olah, G. A. Catal. Lett. 1992, 16, 27-38.

(21) Zhou, X.-P.; Yilmaz, A.; Yilmaz, G. A.; Lorkovic, I. M.; Laverman, L. E.; Weiss, M.; Sherman, J. H.; McFarland, E. W.; Stucky, G. D.; Ford, P. C. Chem. Commun. 2003, 2294-2295.

(22) Lorkovic, I. M.; Noy, M. L.; Schenck, W. A.; Belon, C.; Weiss, M.; Sun, S.; Sherman, J. H.; McFarland, E. W.; Stucky, G. D.; Ford, P. C. Catal. Today 2004, 98, 589-594. 
(23) Breed, A.; Doherty, M. F.; Gadewar, S.; Grosso, P.; Lorkovic, I. M.; McFarland, E. W.; Weiss, M. J. Catal. Today 2005, 106, 301-304.

(24) Degirmenci, V.; Uner, D.; Yilmaz, A. Catal. Today 2005, 106, 252-255.

(25) Lorkovic, I. M.; Sun, S.; Gadewar, S.; Breed, A.; Macala, G. S.; Sardar, A.; Cross, S. E.; Sherman, J. H.; Stucky, G. D.; Ford, P. C. J. Phys. Chem. A 2006, 110, 8695-8700.

(26) Degirmenci, V.; Yilmaz, A.; Uner, D. Catal. Today 2009, 142, 30-33.

(27) Ding, K. L.; Metiu, H.; Stucky, G. D. ACS Catal. 2013, 3, 474-477.

(28) Taylor, C. E.; Noceti, R. P.; Schehl, R. R. Stud. Surf. Sci. Catal. 1988, 36, 483-489.

(29) Peringer, E.; Podkolzin, S. G.; Jones, M. E.; Olindo, R.; Lercher, J. A. Top. Catal. 2006, 38, 211-220.

(30) Wang, K. X.; Xu, H. F.; Li, W. S.; Au, C. T.; Zhou, X. P. Appl. Catal., A 2006, 304, $168-177$.

(31) Podkolzin, S. G.; Stangland, E. E.; Jones, M. E.; Peringer, E.; Lercher, J. A. J. Am. Chem. Soc. 2007, 129, 2569-2576.

(32) Lin, R.; Ding, Y.; Gong, L.; Dong, W.; Wang, J.; Zhang, T. J. Catal. 2010, 272, 65-73.

(33) He, J.; Xu, T.; Wang, Z.; Zhang, Q.; Deng, W.; Wang, Y. Angew. Chem. Int. Ed. 2012, $51,2438-2442$.

(34) Paunović, V.; Zichittella, G.; Moser, M.; Amrute, A. P.; Pérez-Ramírez, J. Nat. Chem. 2016, 8, 803-809.

(35) Olsbye, U.; Saure, O. V.; Muddada, N. B.; Bordiga, S.; Lamberti, C.; Nilsen, M. H.; Lillerud, K. P.; Svelle, S. Catal. Today 2011, 171, 211-220.

(36) Pérez-Ramírez, J.; Mondelli, C.; Schmidt, T.; Schlüter, O. F.-K.; Wolf, A.; Mleczko, L.; Dreier, T. Energ. Environ. Sci. 2011, 4, 4786-4799. 
(37) Moser, M.; Rodríguez-García, L.; Amrute, A. P.; Pérez-Ramírez, J. ChemCatChem 2013, 5, 3520-3523.

(38) Moser, M.; Czekaj, I.; López, N.; Pérez-Ramírez, J. Angew. Chem. Int. Ed. 2014, 53, 8628-8633.

(39) Li, B; Metiu, H. J. Phys. Chem. C 2012, 16, 4137-4148.

(40) Deacon, H. U.S. Patent 85,370, 1868.

(41) Leofanti, G.; Marsella, A.; Cremaschi, B.; Garilli, M.; Zecchina, A.; Spoto, G.; Bordiga, S.; Fisicaro, P.; Berlier, G.; Prestipino, C.; Casali, G.; Lamberti, C. J. Catal. 2001, 202, 279-295.

(42) Brunauer, S.; Emmet, P. H.; Teller, E. J. Am. Chem. Soc. 1938, 60, 309-319.

(43) Derouane, E. G.; Lemos, F.; Corma, A.; Ramôa Ribeiro, F., Combinatorial Catalysis and High Throughput Catalyst Design and Testing; Springer-Science: Netherlands, 1999; Vol 560.

(44) Bierhals, J., Carbon Monoxide. In Ullmann's Encyclopedia of Industrial Chemistry; Wiley-VCH: Weinheim, 2001; Vol. 6, p 679.

(45) Hu, Z.; Metiu, H. J. Phys. Chem. C 2012, 116, 6664-6671.

(46) Amrute, A. P.; Mondelli, C.; Moser, M.; Novell-Leruth, G.; López, N.; Rosenthal, D.; Farra, R.; Schuster, M. E.; Teschner, D.; Schmidt, T.; Pérez-Ramírez, J. J. Catal. 2012, 286, 287-297.

(47) Teschner, D.; Farra, R.; Yao, L.; Schlögl, R.; Soerijanto, H.; Schomäcker, R.; Schmidt, T.; Szentmiklósi, L.; Amrute, A. P.; Mondelli, C.; Pérez-Ramírez, J.; Novell-Leruth, G.; López, N. J. Catal. 2012, 285, 273-284. 
(48) Teschner, D.; Novell-Leruth, G.; Farra, R.; Knop-Gericke, A.; Schlögl, R.; Szentmiklosi, L.; Hevia, M. G.; Soerijanto, H.; Schomacker, R.; Pérez-Ramírez, J.; López, N. Nat. Chem. 2012, 4, 739-745.

(49) Moser, M.; Vilé, G.; Colussi, S.; Krumeich, F.; Teschner, D.; Szentmiklósi, L.; Trovarelli, A.; Pérez-Ramírez, J. J. Catal. 2015, 331, 128-137.

(50) Moser, M.; Paunović, V.; Guo, Z.; Szentmiklósi, L.; Hevia, M. G.; Higham, M.; López, N.; Teschner, D.; Pérez-Ramírez, J. Chem. Sci. 2016, 7, 2996-3005.

(51) Moser, M.; Amrute, A. P.; Pérez-Ramírez, J. Appl. Catal., B 2015, 162, 602-609. 
Table 1. Reactions and feed compositions studied in this work.

\begin{tabular}{|c|c|c|c|c|c|c|c|c|}
\hline \multirow{2}{*}{ Reaction } & \multicolumn{8}{|c|}{ Concentration / vol.\% } \\
\hline & $\mathrm{CH}_{4}$ & $\mathrm{CH}_{2} \mathrm{X}_{2}$ & $\mathrm{CO}$ & HX & $\mathrm{X}_{2}$ & $\mathrm{O}_{2}$ & $\mathrm{Ar}$ & $\mathrm{He}$ \\
\hline $\mathrm{CH}_{4}$ oxyhalogenation & 6 & - & - & $3-15$ & - & 3 & 4.5 & $83.5-71.5$ \\
\hline $\mathrm{CH}_{4}$ chlorination & 6 & - & - & - & 1.75 & - & 4.5 & 87.75 \\
\hline $\mathrm{CH}_{4}$ bromination & 6 & - & - & - & 2.7 & - & 4.5 & 86.8 \\
\hline $\mathrm{CH}_{4}$ oxidation & 6 & - & - & - & - & 3 & 4.5 & 86.5 \\
\hline $\mathrm{CH}_{2} \mathrm{X}_{2}$ oxidation & - & 1 & - & 0 or 6 & - & 3 & 4.5 & 91.5 or 85.5 \\
\hline CO oxidation & - & - & 1 & 0 or 6 & - & 3 & 4.5 & 91.5 or 85.5 \\
\hline HX oxidation & - & - & - & 6 & - & 3 & 4.5 & 86.5 \\
\hline
\end{tabular}


Table 2. Surface halogen content determined by XPS measurements of the samples prior to (fresh), and after MOC and MOB.

\begin{tabular}{|c|c|c|}
\hline Sample & Cl:Ce / - & $\mathrm{Br}: \mathrm{Ce} /$ - \\
\hline fresh & 0.018 & 0 \\
\hline MOC-6 ${ }^{a}$ & 0.136 & 0 \\
\hline MOC- $15^{a}$ & 0.135 & 0 \\
\hline MOB-6 & 0.011 & 0.068 \\
\hline MOB-15 & 0 & 0.128 \\
\hline
\end{tabular}




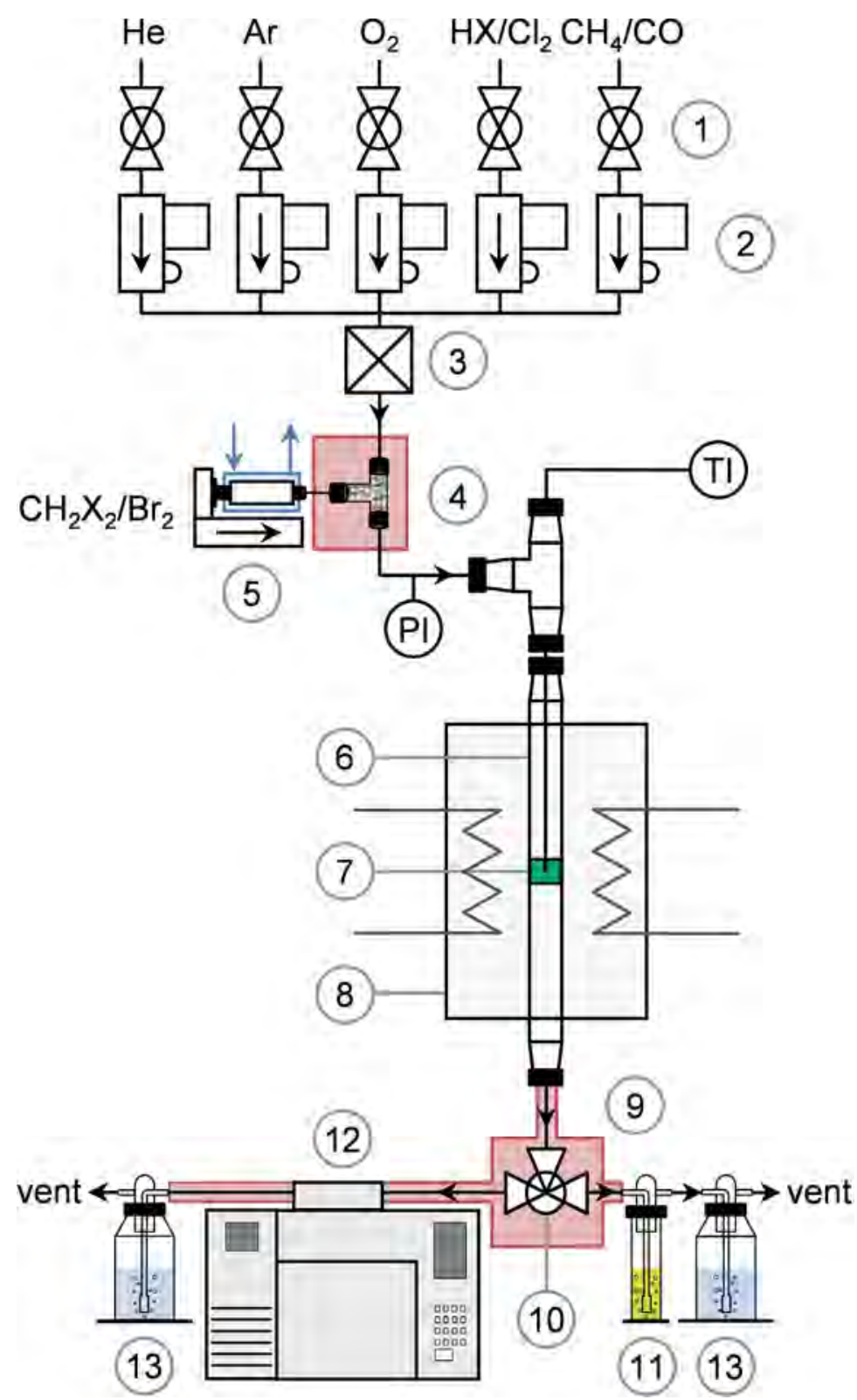

Scheme 1. Flowsheet of the laboratory set-up for the continuous-flow oxyhalogenation of methane. 1: two-way on-off valves, 2: mass flow controllers, 3: mixer, 4: vaporizer, 5: syringe pump with water-cooling system, 6: quartz reactor, 7: catalyst bed, 8: oven, 9: heat tracing, 10: three-way sampling valve, 11: KI impinging bottle, 12: GC-MS, 13: $\mathrm{NaOH}$ scrubbers, PI: pressure indicator, and TI: temperature indicator. 


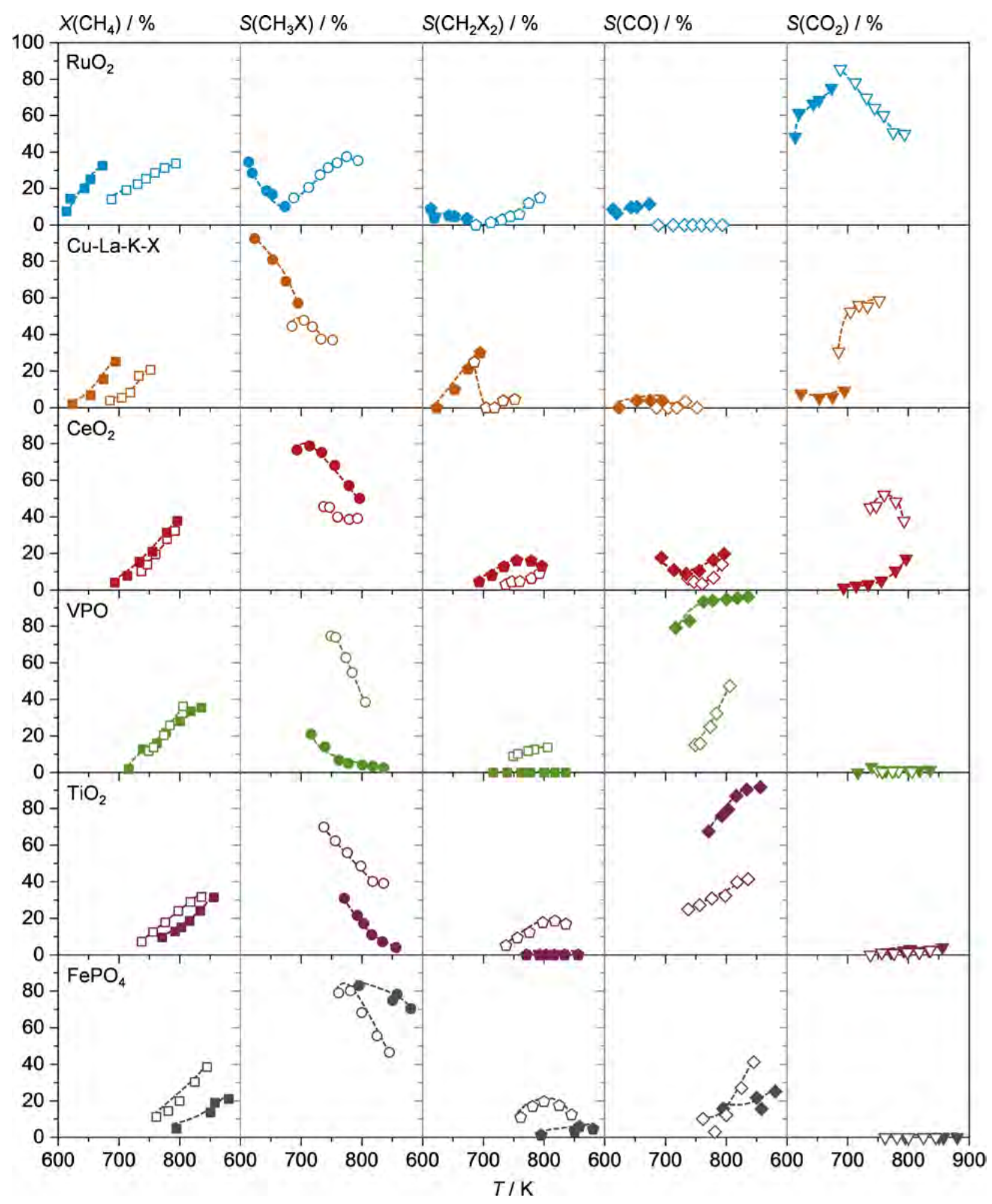

Figure 1. Conversion and product selectivity versus temperature in MOC (solid symbols) and MOB (open symbols) over the catalysts. Conditions: $\mathrm{CH}_{4}: \mathrm{HX}: \mathrm{O}_{2}: \mathrm{Ar}: \mathrm{He}=6: 6: 3: 4.5: 80.5$. 


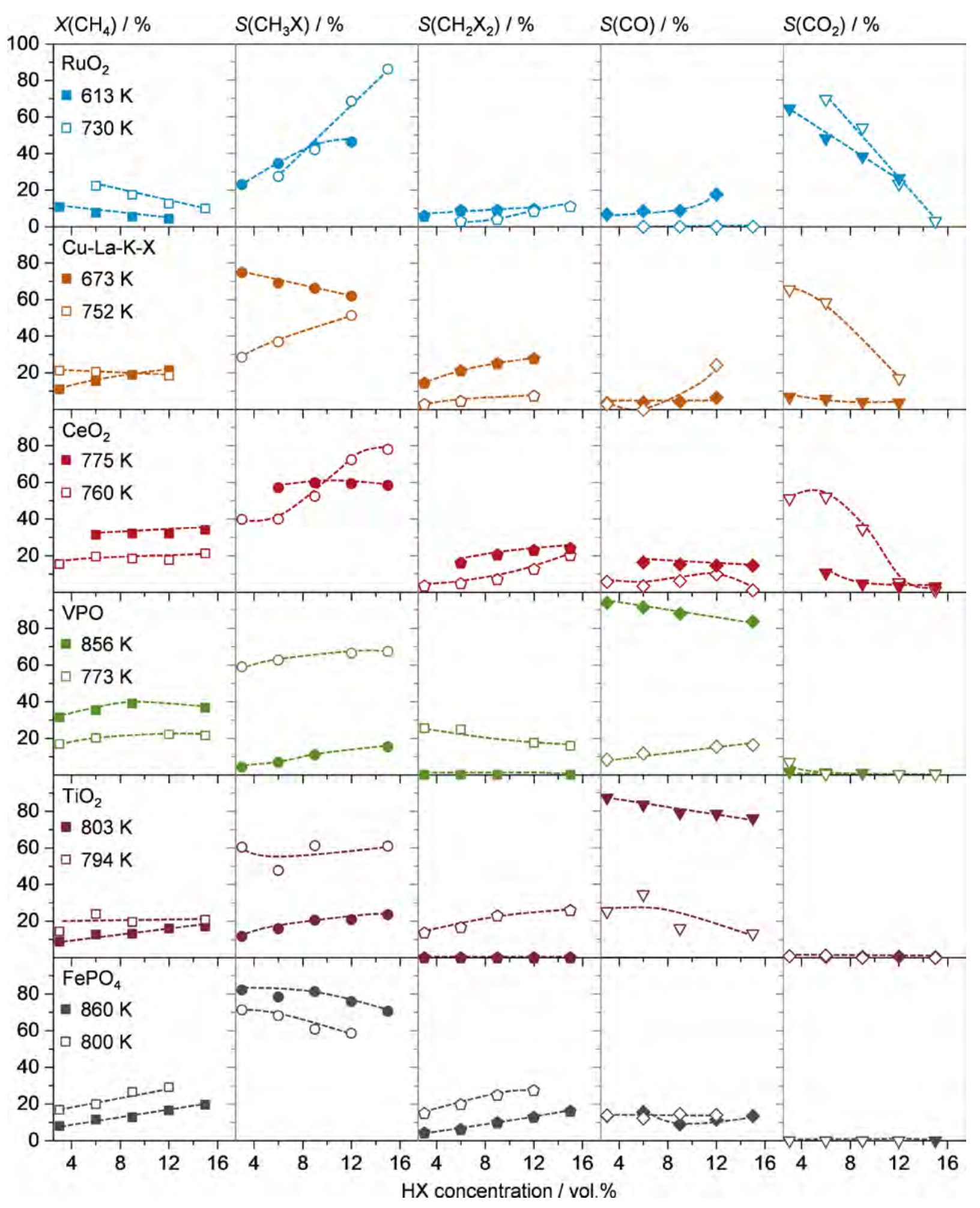

Figure 2. Conversion and product selectivity versus feed HX concentration in MOC (solid symbols) and MOB (open symbols) over the catalysts. Conditions: $\mathrm{CH}_{4}: \mathrm{HX}: \mathrm{O}_{2}: \mathrm{Ar}: \mathrm{He}=6: 3-$ 15:3:4.5:83.5-71.5. 


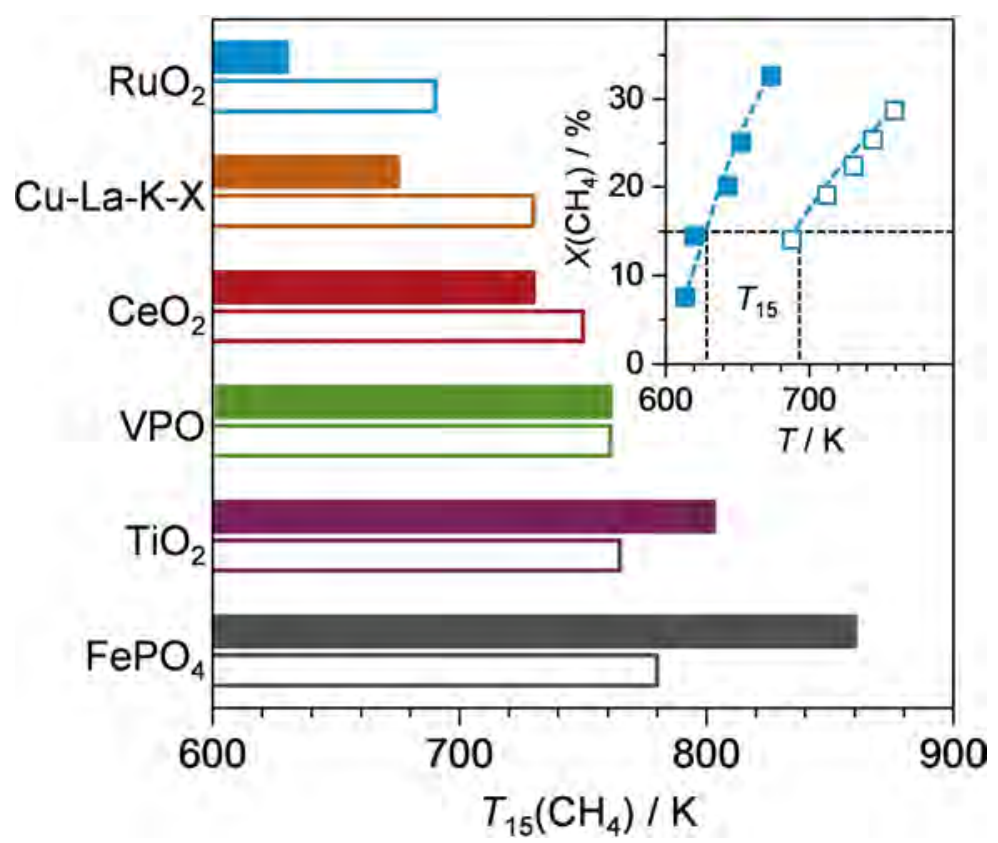

Figure 3. Temperature required to attain 15\% conversion ( $\left.T_{15}\right)$ in MOC (solid bars) and MOB (open bars) over the catalysts. The inset exemplifies the determination of $T_{15}$ in MOC and MOB for $\mathrm{RuO}_{2}$. 


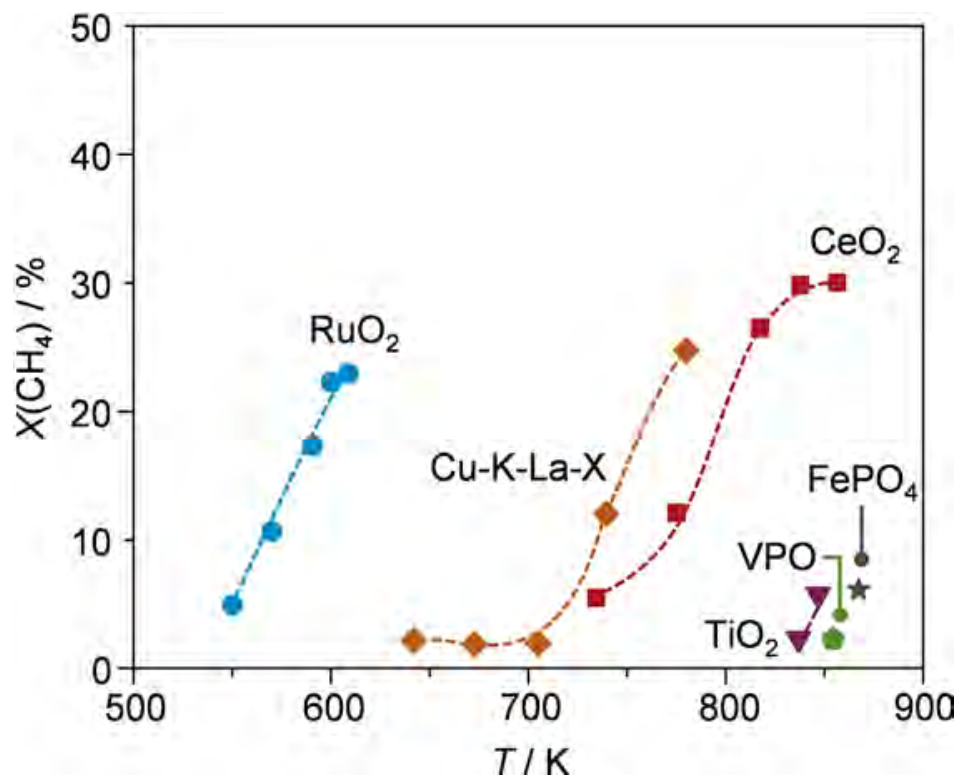

Figure 4. Conversion versus temperature in methane oxidation over the catalysts. Conditions: $\mathrm{CH}_{4}: \mathrm{O}_{2}: \mathrm{Ar}: \mathrm{He}=6: 3: 4.5: 86.5$. 


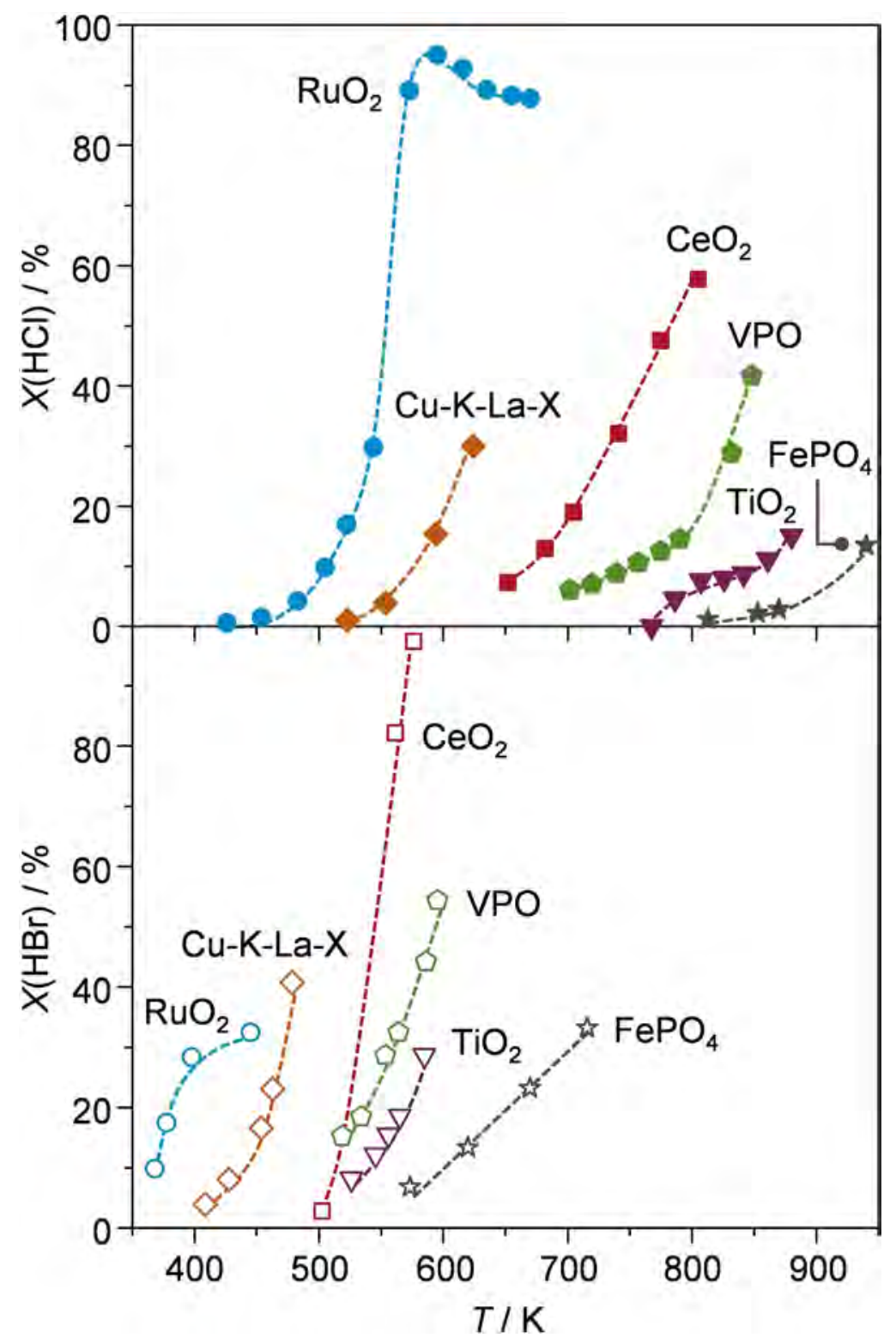

Figure 5. Conversion versus temperature in $\mathrm{HCl}$ (top) and $\mathrm{HBr}$ (bottom) oxidation over the catalysts. Conditions: $\mathrm{HX}: \mathrm{O}_{2}: \mathrm{Ar}: \mathrm{He}=6: 3: 4.5: 86.5$. 

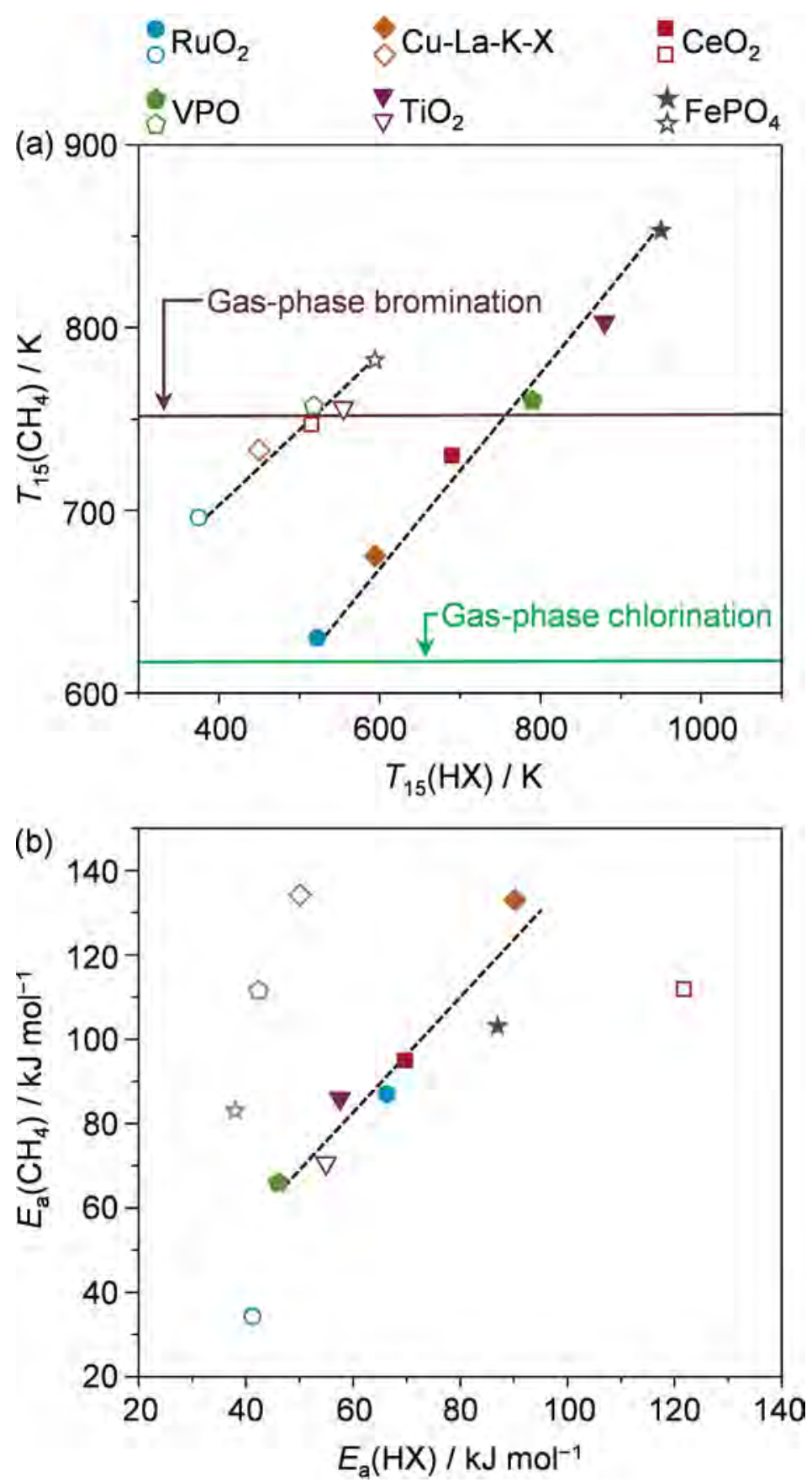

Figure 6. (a) Temperature required to attain 15\% conversion and (b) apparent activation energy in methane oxyhalogenation versus HX oxidation over the catalysts. The green and brown lines in (a) denote $T_{15}\left(\mathrm{CH}_{4}\right)$ in the gas-phase methane chlorination and bromination experiments, respectively. $\mathrm{HCl}$ : solid symbols; $\mathrm{HBr}$ : open symbols. 


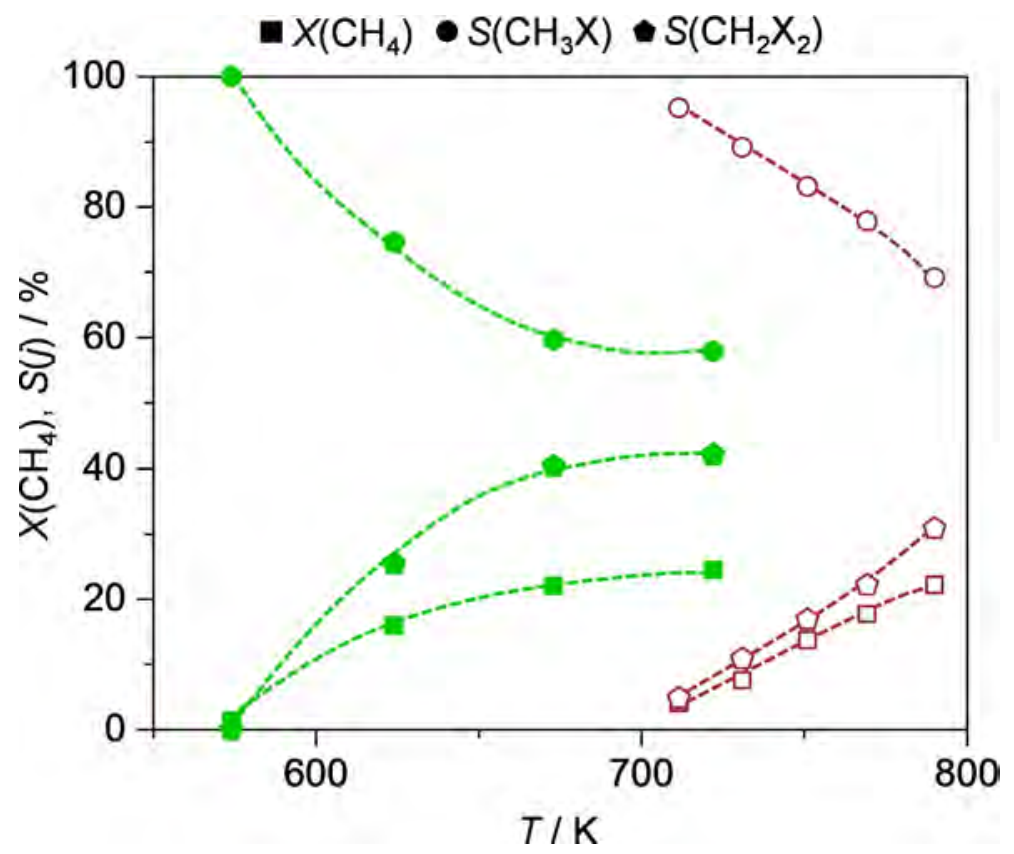

Figure 7. Conversion and product selectivity versus temperature in methane chlorination (solid symbols) and bromination (open symbols). Conditions: $\mathrm{CH}_{4}: \mathrm{Cl}_{2}: \mathrm{O}_{2}: \mathrm{Ar}: \mathrm{He}=6: 1.75: 3: 4.5: 87.75$; $\mathrm{CH}_{4}: \mathrm{Br}_{2}: \mathrm{O}_{2}: \mathrm{Ar}: \mathrm{He}=6: 2.7: 3: 4.5: 86.8$. 


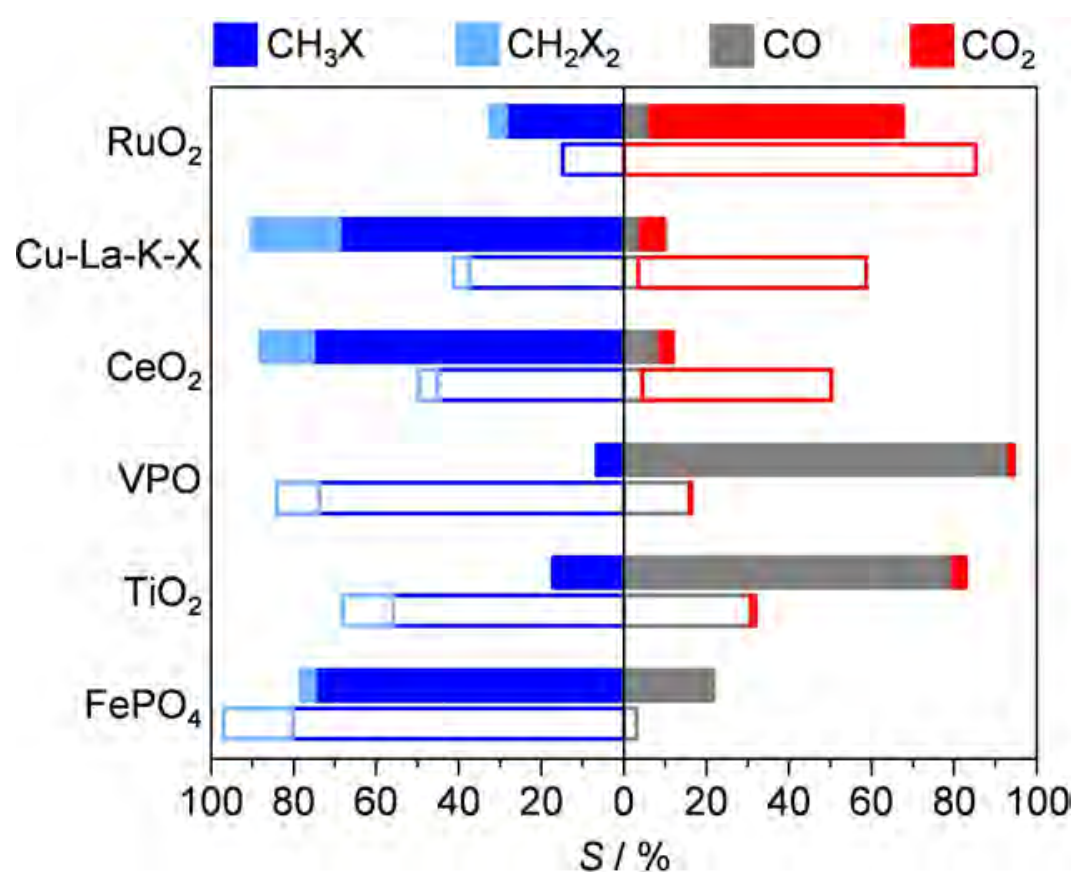

Figure 8. Product selectivity at ca. 15\% conversion in MOC (solid bars) and MOB (open bars) over the catalysts. 

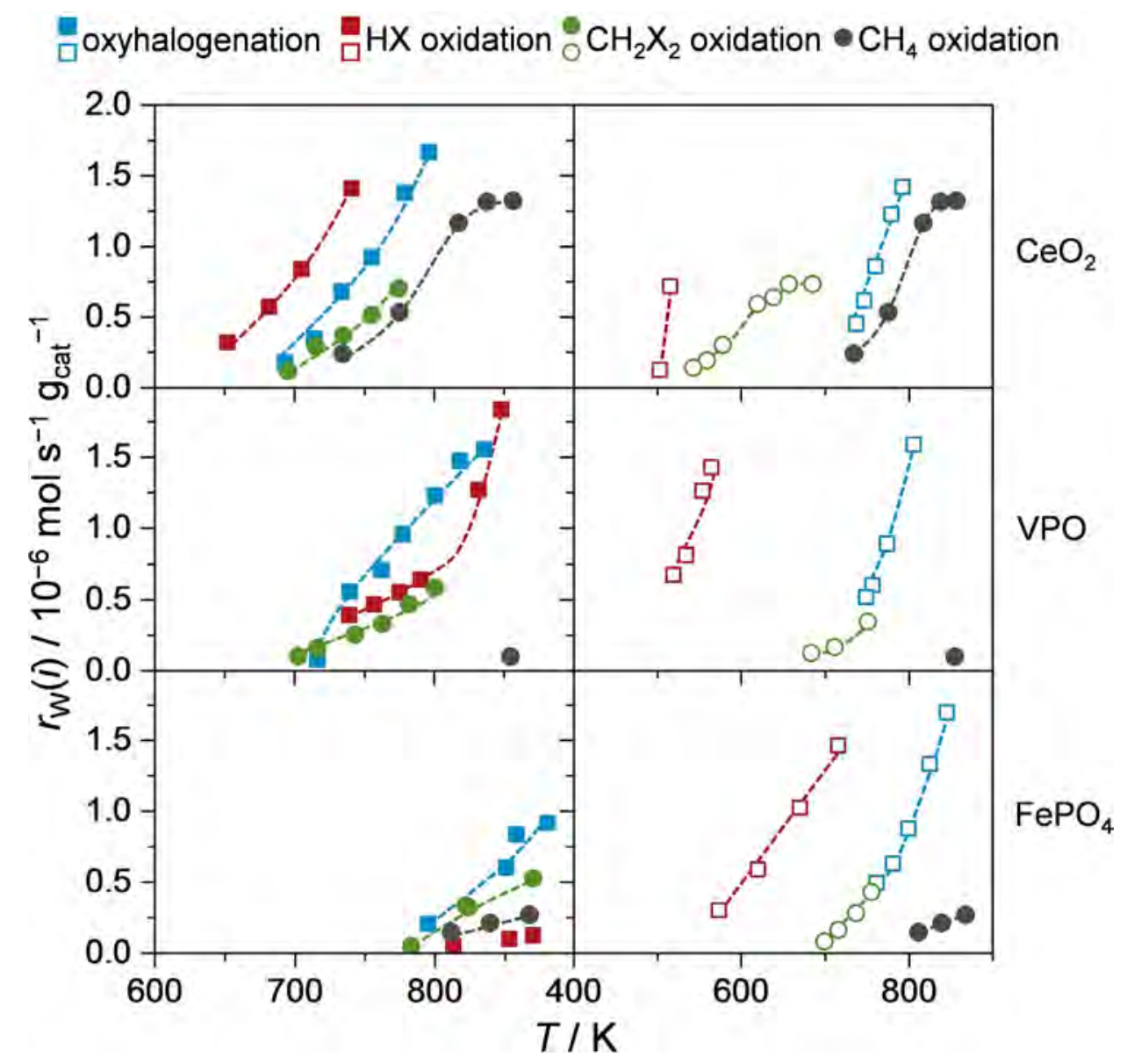

Figure 9. Reaction rates versus temperature of $\mathrm{CeO}_{2}, \mathrm{VPO}$, and $\mathrm{FePO}_{4}$ in oxyhalogenation (blue), $\mathrm{HX}$ (red), $\mathrm{CH}_{2} \mathrm{X}_{2}$ (green), and $\mathrm{CH}_{4}$ (grey) oxidation. $\mathrm{X}=\mathrm{Cl}$ : solid symbols; $\mathrm{X}=\mathrm{Br}$ : open symbols. $\mathrm{CH}_{4}: \mathrm{HX}: \mathrm{O}_{2}: \mathrm{Ar}: \mathrm{He}=6: 6: 3: 4.5: 80.5$ (blue symbols); $\mathrm{HX}: \mathrm{O}_{2}: \mathrm{Ar}: \mathrm{He}=6: 3: 4.5: 86.5$ (red symbols); $\mathrm{CH}_{2} \mathrm{X}_{2}: \mathrm{O}_{2}: \mathrm{Ar}: \mathrm{He}=1: 0: 3: 4.5: 91.5$ (green symbols); $\mathrm{CH}_{4}: \mathrm{O}_{2}: \mathrm{Ar}: \mathrm{He}=6: 0: 3: 4.5: 86.5$ (grey symbols). 

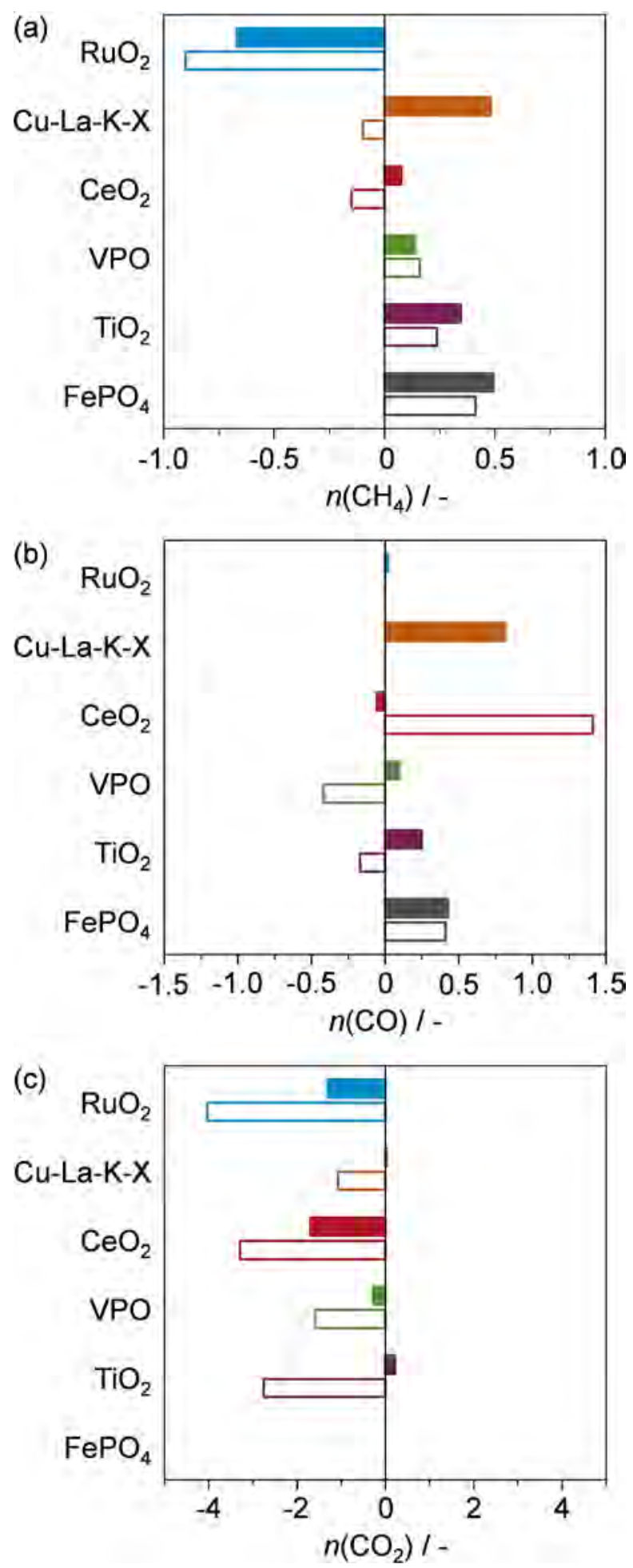

Figure 10. Apparent partial orders for (a) methane conversion, and (b) $\mathrm{CO}$ and (c) $\mathrm{CO}_{2}$ formation, obtained by the variation of feed HX concentration in MOC (solid bars) and MOB (open bars) over the catalysts. 

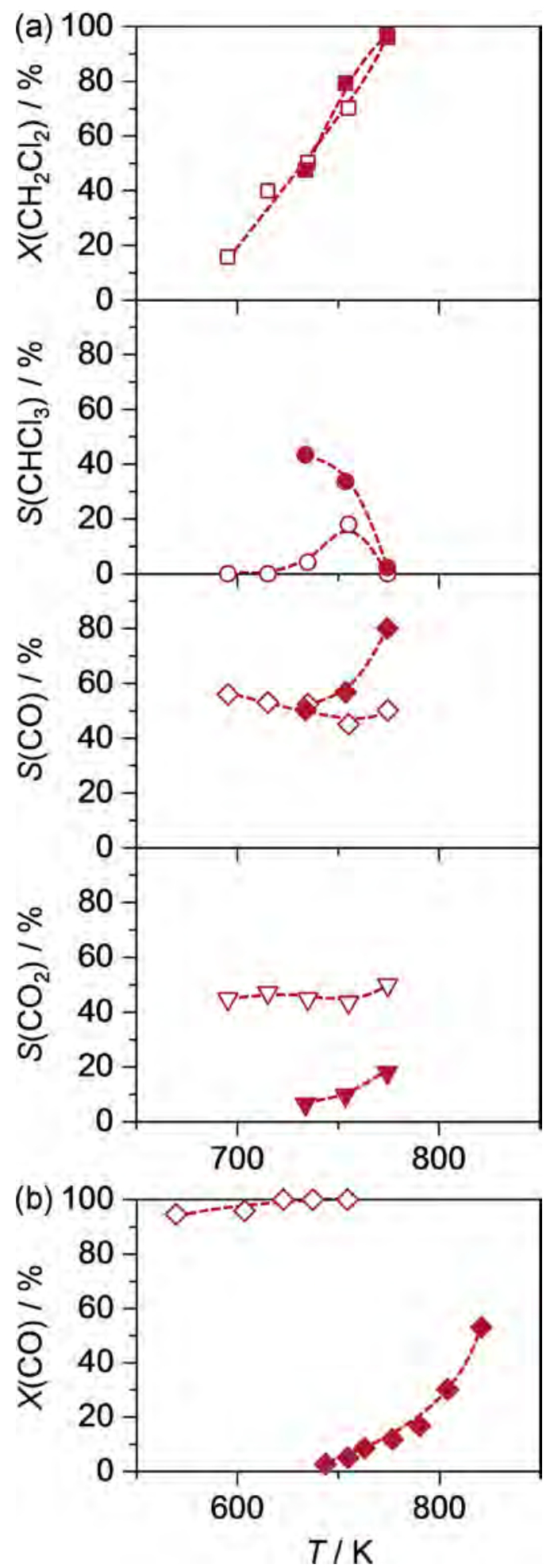

Figure 11. Conversion and product selectivity versus temperature in (a) $\mathrm{CH}_{2} \mathrm{Cl}_{2}$ and (b) $\mathrm{CO}$ oxidation over $\mathrm{CeO}_{2}$. Conditions: $\mathrm{CH}_{2} \mathrm{Cl}_{2} / \mathrm{CO}: \mathrm{O}_{2}$ :Ar:He = 1:3:4.5:91.5 (open symbols); $\mathrm{CH}_{2} \mathrm{Cl}_{2} / \mathrm{CO}: \mathrm{HCl}: \mathrm{O}_{2}: \mathrm{Ar}: \mathrm{He}=$ 1:6:3:4.5:85.5 (solid symbols). 
- $\mathrm{RuO}_{2} \triangleq \mathrm{Cu}-\mathrm{K}-\mathrm{La}-\mathrm{X} \quad \mathrm{CeO}_{2} \triangleq \mathrm{VPO} \quad \boldsymbol{\nabla} \mathrm{TiO}_{2} \quad \star \mathrm{FePO}_{4}$
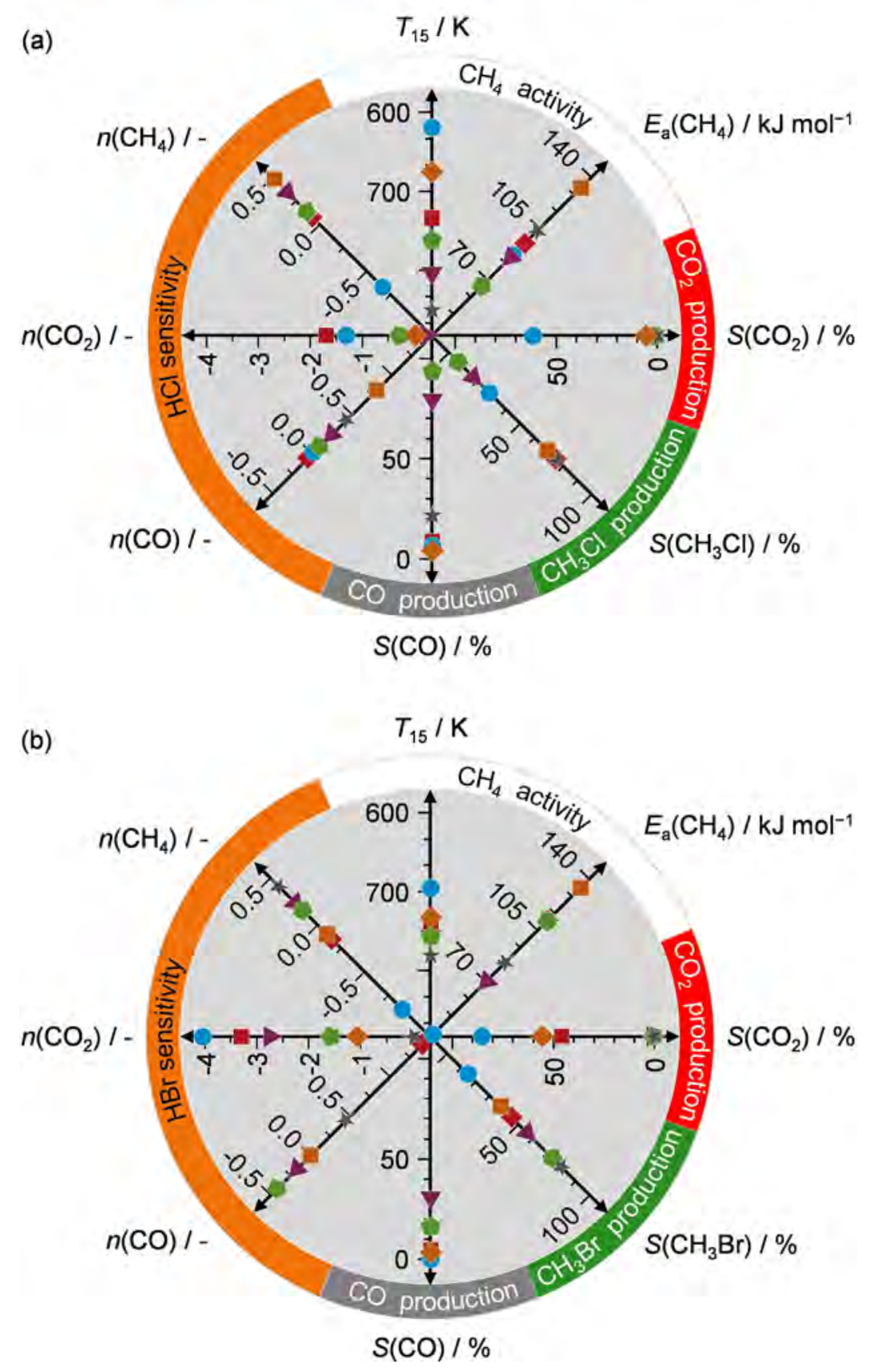

Figure 12. Overview of the catalytic descriptors in (a) MOC and (b) MOB, extracted from the experimental program (Figure 1 and 2). The upper half of the radar charts classifies a material as a good oxyhalogenation catalyst if it combines high activity (low $T_{15}$, high $\left.E_{a}\left(\mathrm{CH}_{4}\right), n\left(\mathrm{CH}_{4}\right)>0\right)$, and low tendency to $\mathrm{CO}_{2}$ formation (low $S\left(\mathrm{CO}_{2}\right), n\left(\mathrm{CO}_{2}\right)<0$ ) even increased by inlet $\mathrm{HX}$ 
addition, which will be displayed centrifugally in this part of the plot. The bottom half, instead, classifies materials for their ability to produce $\mathrm{CH}_{3} \mathrm{X}$ (high $\mathrm{S}\left(\mathrm{CH}_{3} \mathrm{X}\right)$ ), if they lay on the outer annulus of the plot, or as $\mathrm{CO}$ generators (high $S(\mathrm{CO})$, and $n(\mathrm{CO})$ ), if they converge to the center of the chart. 
Table of Contents Graphic

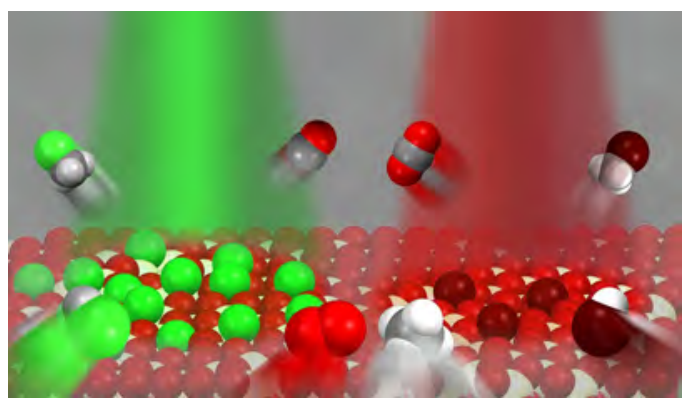




\section{Supporting Information}

\section{Catalytic Oxychlorination versus Oxybromination for Methane Functionalization}

Guido Zichittella, ${ }^{\dagger}$ Vladimir Paunović, ${ }^{\dagger}$ Amol P. Amrute, Javier Pérez-Ramírez*

Institute for Chemical and Bioengineering, Department of Chemistry and Applied Biosciences, ETH Zurich, VladimirPrelog-Weg 1, 8093 Zurich, Switzerland

${ }^{\dagger}$ Equal contribution. |* Corresponding author. E-mail: jpr@chem.ethz.ch 


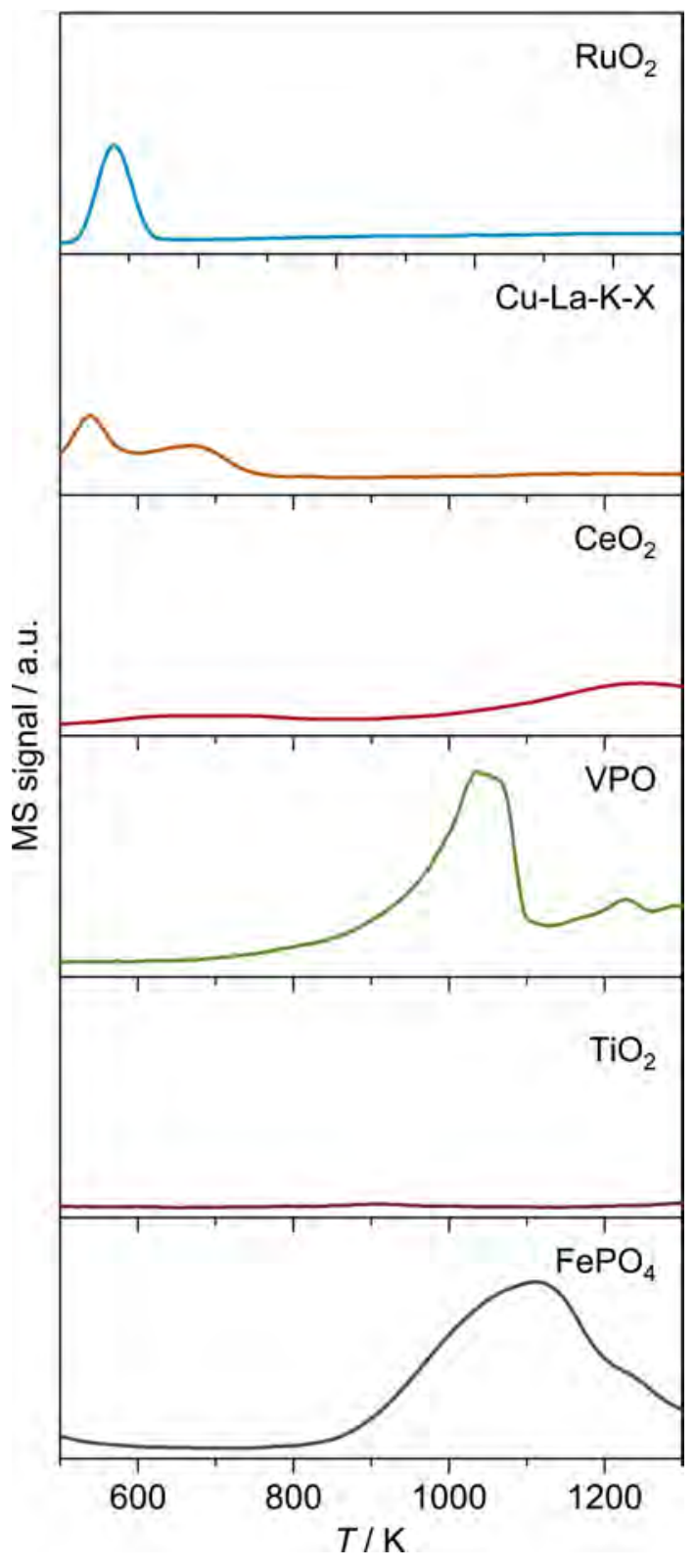

Figure S1. $\mathrm{H}_{2}$-TPR profiles, classifying the reducibility property based on the onset of $\mathrm{H}_{2}$ consumption, of the fresh catalysts. 
Table S1. Total surface area of the samples, $S_{\mathrm{BET}}$, prior to (fresh), and after MOC and MOB.

\begin{tabular}{lccc}
\hline & \multicolumn{3}{c}{$S_{\mathrm{BET}} / \mathrm{m}^{2} \mathrm{~g}^{-1}$} \\
\cline { 2 - 4 } Catalyst & fresh & MOC & MOB \\
\hline $\mathrm{RuO}_{2}$ & 9 & 9 & 11 \\
$\mathrm{Cu}-\mathrm{K}-\mathrm{La}-\mathrm{X}$ & 92 & 141 & 142 \\
$\mathrm{CeO}$ & & 16 & 21 \\
$\mathrm{VPO}$ & 34 & 25 & 20 \\
$\mathrm{TiO}_{2}$ & 30 & 14 & 13 \\
$\mathrm{FePO}_{4}$ & 19 & 2 & 2 \\
\hline
\end{tabular}

Table S2. Apparent activation energy, $E_{a}\left(\mathrm{CH}_{4}\right)$, and partial orders with respect to $\mathrm{HX}, n\left(\mathrm{CH}_{4}\right), n(\mathrm{CO}), n\left(\mathrm{CO}_{2}\right)$, over the catalysts in MOC and MOB, derived from FigureS6 and S7, respectively.

\begin{tabular}{lccccc}
\hline Catalyst & Reaction & $E_{a}\left(\mathrm{CH}_{4}\right) / \mathrm{kJ} \mathrm{mol}^{-1}$ & $n\left(\mathrm{CH}_{4}\right) /-$ & $n(\mathrm{CO}) /-$ & $n\left(\mathrm{CO}_{2}\right) /-$ \\
\hline $\mathrm{RuO}_{2}$ & MOC & 86 & -0.67 & 0.01 & -1.30 \\
& MOB & 34 & -0.90 & - & -4.01 \\
$\mathrm{Cu}-\mathrm{K}-\mathrm{La}-\mathrm{X}$ & MOC & 134 & 0.48 & 0.02 & 0.02 \\
& MOB & 133 & -0.11 & -1.07 & -1.07 \\
$\mathrm{CeO}_{2}$ & MOC & 111 & 0.08 & -0.06 & -1.69 \\
& MOB & 71 & -0.15 & 1.41 & -3.30 \\
$\mathrm{VPO}$ & MOC & 66 & 0.14 & 0.09 & -0.28 \\
& MOB & 111 & 0.15 & -0.41 & -1.57 \\
$\mathrm{TiO}_{2}$ & MOC & 85 & 0.34 & 0.25 & -1.70 \\
& MOB & 71 & 0.23 & -0.17 & 0.22 \\
$\mathrm{FePO}_{4}$ & MOC & 103 & 0.49 & 0.44 & - \\
& MOB & 83 & 0.41 & 0.09 & - \\
\hline
\end{tabular}




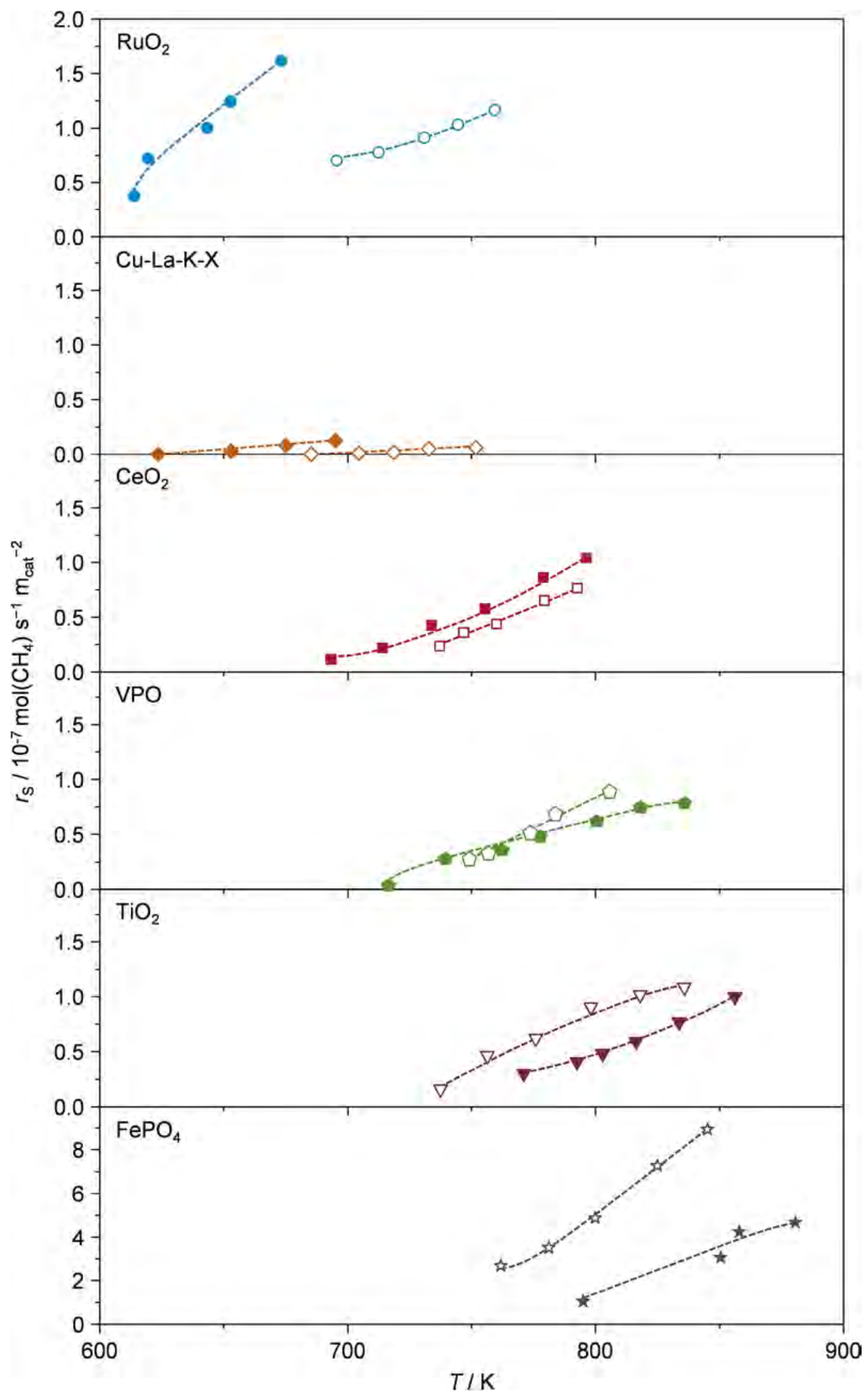

Figure S2. Normalization of the activity in methane oxyhalogenation with respect to the surface area of the used material, which was calculated according to Eq. 8 provided in the Experimental section. The comparison of the catalytic activities in MOB and MOC, as well as the activity comparison for the same reaction can be achieved in 
several ways. Rigorously, turn-over frequency (TOF) is the recommended measure of the inherent catalytic activity (Combinatorial Catalysis and High Throughput Catalyst Design and Testing 2000, Vol. 560, Springer, Netherlands), which however necessitates the exact knowledge about the number of the active sites. A commonly used approximation of TOF is based on normalization of the reaction rate with respect to the surface area. If this approach is applied, the following order of activities in MOC: $\mathrm{RuO}_{2}>\mathrm{CeO}_{2} \sim \mathrm{Cu}-\mathrm{K}-\mathrm{La}-\mathrm{X} \sim \mathrm{FePO}_{4}>\mathrm{VPO}>\mathrm{TiO}_{2}$, and MOB: $\mathrm{RuO}_{2} \sim \mathrm{FePO}_{4}>\mathrm{CeO}_{2} \sim \mathrm{VPO} \sim \mathrm{TiO}_{2}>\mathrm{Cu}-\mathrm{K}-\mathrm{La}-\mathrm{X}$. Nevertheless, this expression of activity has a drawback as it implies the surface density of active sites for different types of materials (e.g. oxides and phosphates, or bulk and supported catalysts) to be the same, which is likely not the case. Therefore, the rate per surface area does not necessarily reflect TOF in its core definition, which might lead to some contradictive conclusions, such that supported Cu-based system exhibits a rather low activity, though it is widely accepted as a benchmark oxyhalogenation catalyst. On the other hand, any attempt to estimate the surface density of sites for a real-life, polycrystalline material will necessitate assumptions on the size, shape, or structure of individual particles, which in principle might introduce uncontrolled errors and possible misinterpretation of the results. Moreover, the overall oxyhalogenation performance is possibly affected by the gas-phase contributions (Nat. Chem. 2016, 8, 803-809), which would be incorrectly (and unfairly) ascribed to the surface sites. In an alternative approach, the activation barriers (Table S2) can be used for ranking the catalyst activity, as these are considered as an inherent measure of the active site ability to promote the given reaction, so that highly active catalyst should exhibit the lowest activation barrier. An implementation of this criteria, gives the following order of activity in MOC: VPO $>\mathrm{TiO}_{2}>\mathrm{RuO}_{2}>\mathrm{FePO}_{4}>\mathrm{CeO}_{2}>\mathrm{Cu}-\mathrm{K}-\mathrm{La}-\mathrm{X}$, and in MOB: $\mathrm{RuO}_{2}>\mathrm{TiO}_{2}=\mathrm{CeO}_{2}>\mathrm{FePO}_{4}>\mathrm{VPO}>\mathrm{Cu}-\mathrm{K}-\mathrm{La}-\mathrm{X}$, which is different than the one based on surface- or weight/volume-normalized reaction rates (vide infra). Nevertheless, the complexity of the oxyhalogenation process suggests the activation barriers extracted from the temperature variation experiments likely include contributions from the different heterogeneous and/or homogenous reaction steps that might vary among various oxyhalogenation catalysts. As such, they do not necessarily reflect the intrinsic catalyst propensity to facilitate the halomethane formation, and are thus not considered as an appropriate measure of the catalyst performance. Given the abovementioned challenges, the comparison of the catalytic activities per unit of weight/volume was used, which is a widely accepted approach in catalysis (Combinatorial Catalysis and High Throughput Catalyst Design and Testing 2000, Vol. 560, Springer, Netherlands), also applied in the previous studies on oxyhalogenation (Angew. Chem. Int. Ed. 2012, 51, 2438-2442; Nat. Chem. 2016, 8, 803-809). Therefore, the catalytic tests were performed over a constant weight of a catalyst (1 g), which was mixed with quartz particles to ensure the constant reaction volume $\left.\left(1.8 \mathrm{~cm}^{3}\right)\right)$. Though it does not reflect the surface reactivity of different materials, we find it useful as it 1) provides information on the productivity per unit of space, which is highly relevant for potential reactor and process design, and 2) enables the comparison of the kinetics of different (partially) catalytic and non-catalytic reactions (vide infra), since the rate of the latter is per definition space-dependent. Besides, the differences in the performance among distinct materials are not the primary focus of our study, but more the performance similarities and diversities of a single material in the two oxyhalogenation reactions. Since the measured surface area do not differ significantly among fresh and used samples of the same nature (Table S1), the expression of reaction rate with respect to surface, weight, or volume, does not induce important implications for further discussion. 


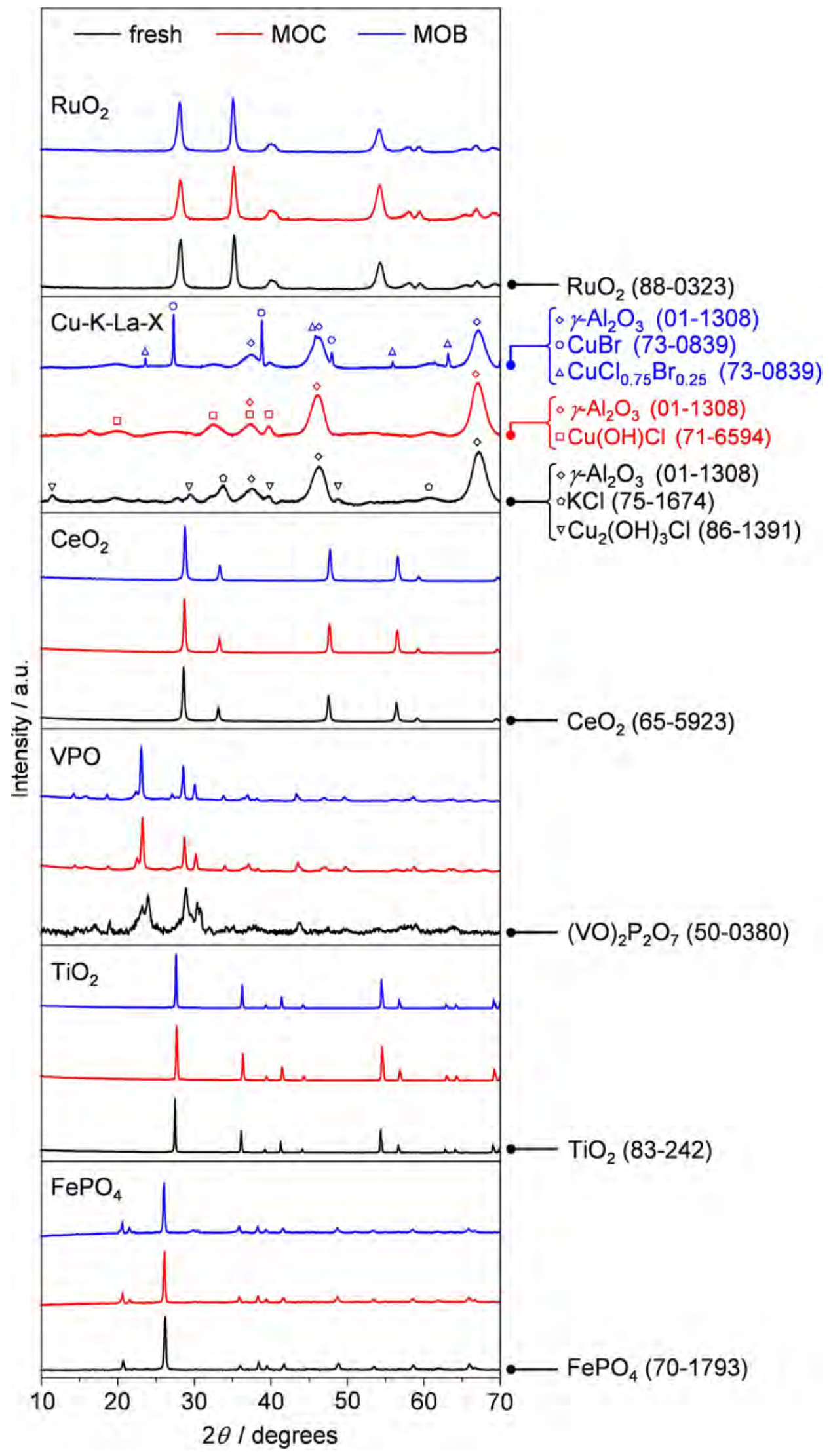

Figure S3. X-ray diffraction patterns of the samples prior to (black), and after MOC (red) and MOB (blue). The right panel provides the identified crystalline phases and ICDD-PDF numbers. 


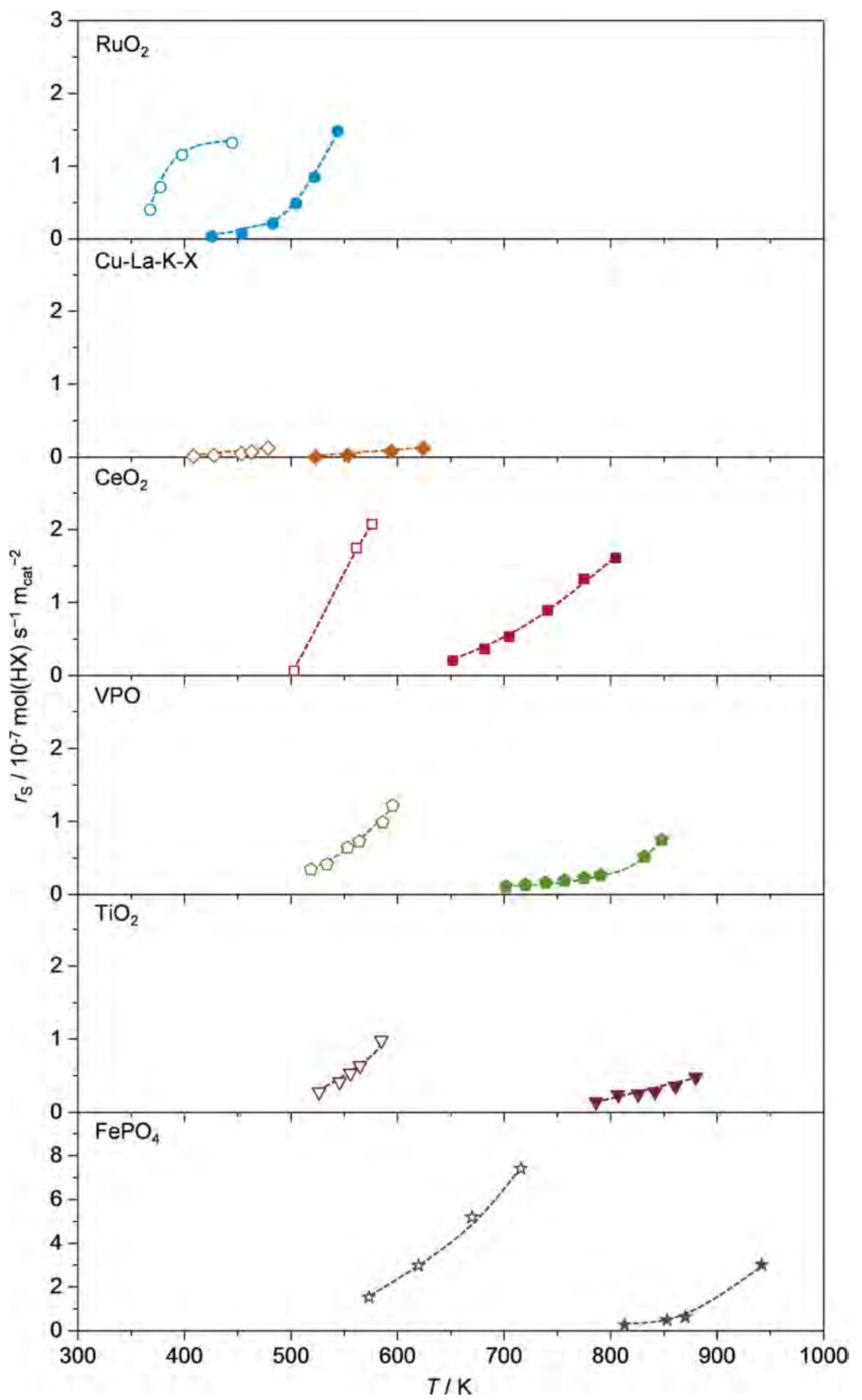

Figure S4. Normalization of the activity in HX oxidation with respect to the surface area of the used material, which was calculated according to Eq. 8 provided in the Experimental section. 


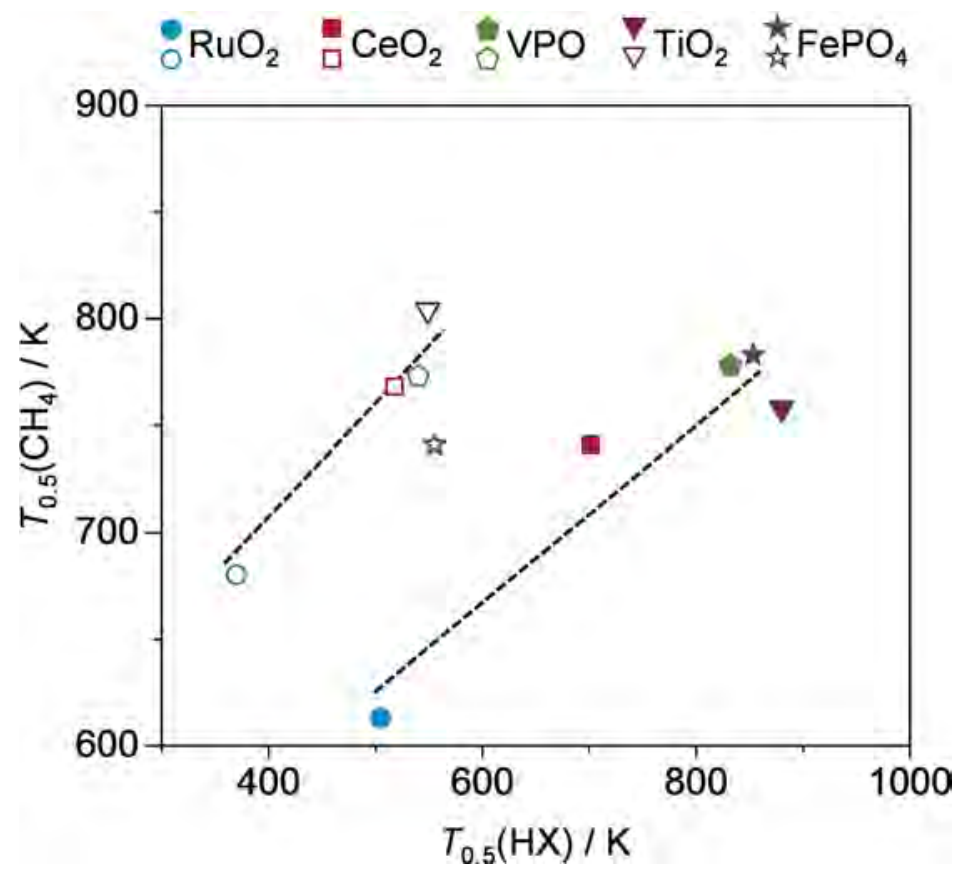

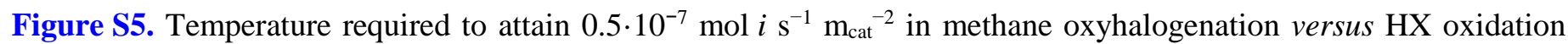
over the catalysts. The correlation observed for the activity with respect to weight is also valid for the activity per unit surface area. 


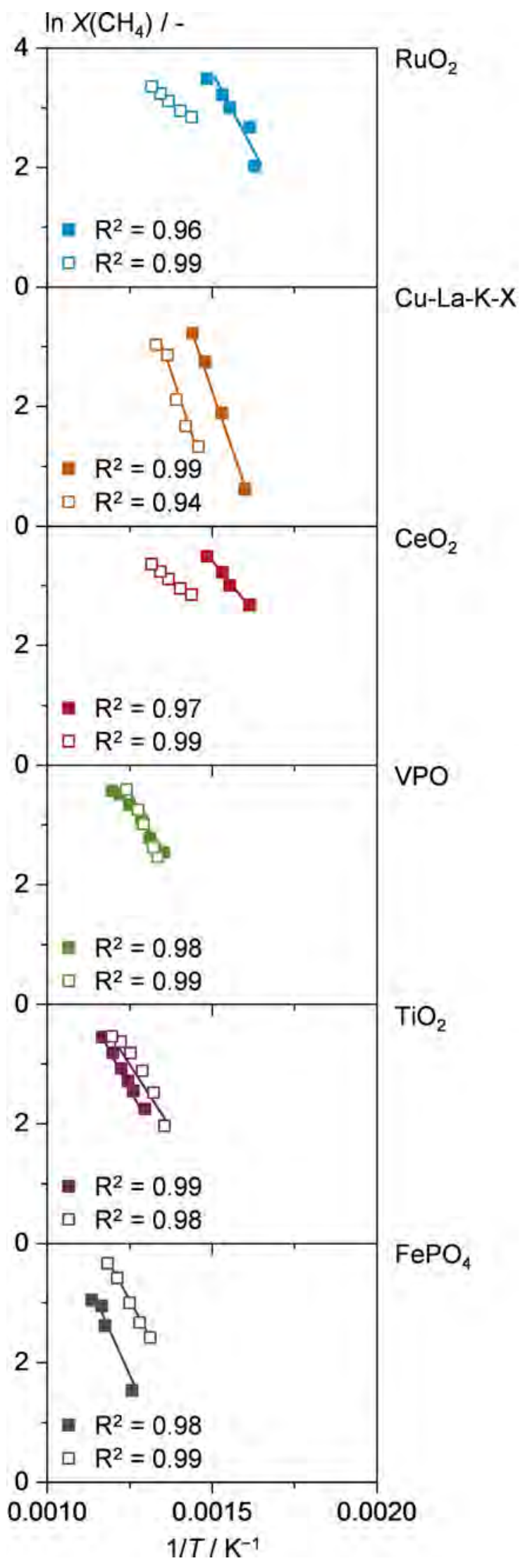

Figure S6. Arrhenius plots for methane conversion in MOC (solid symbols) and MOB (open symbols) over the catalysts. The derived apparent activation energy, $E_{\mathrm{a}}\left(\mathrm{CH}_{4}\right)$, is indicated in Table S2. 


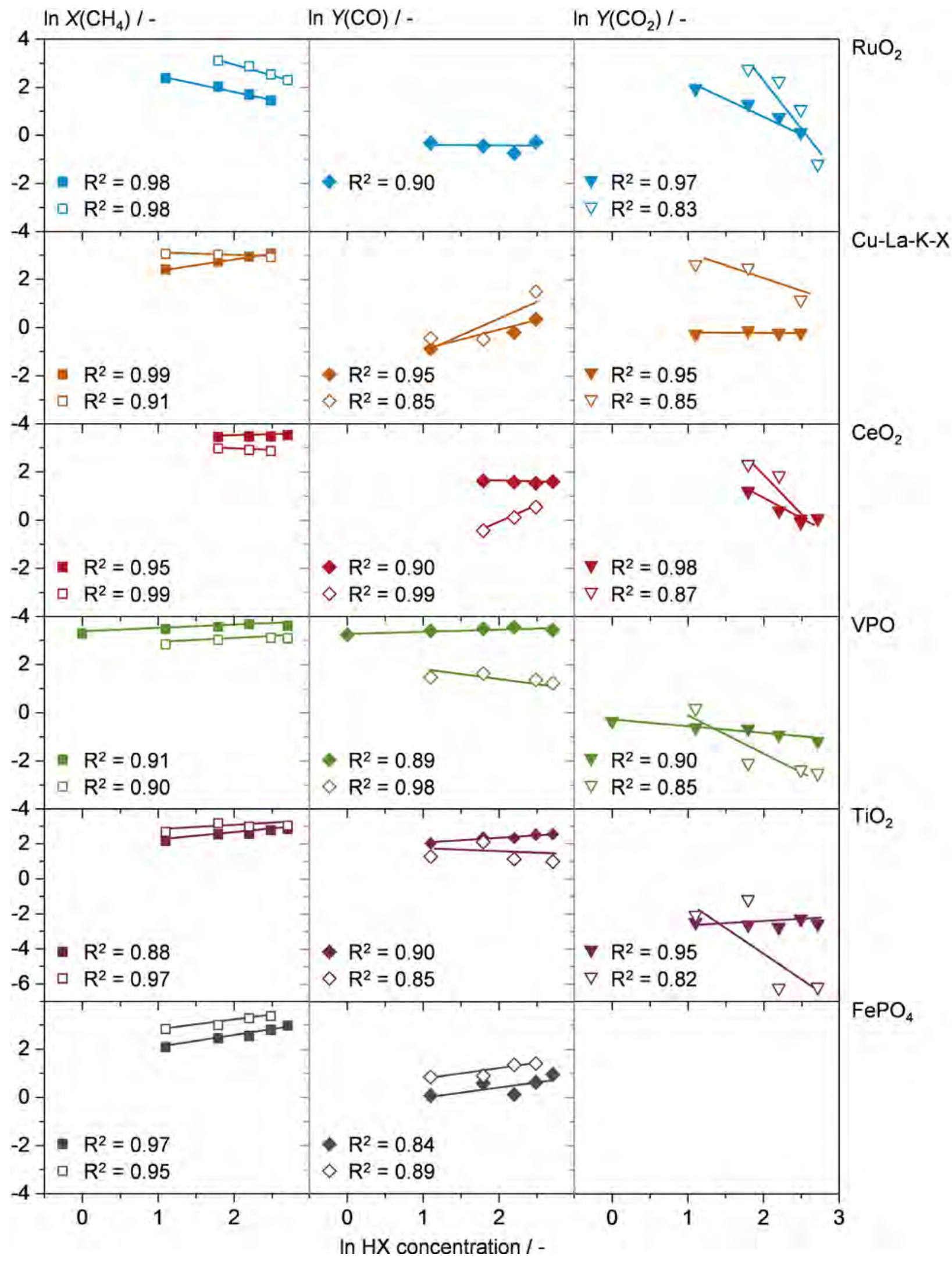

Figure S7. Logarithm of methane conversion (left), and $\mathrm{CO}$ (center) and $\mathrm{CO}_{2}$ (right) yields versus logarithm of feed HX concentration in MOC (solid symbols) and MOB (open symbols) over the catalysts. The derived apparent partial orders with respect to $\mathrm{HX}, n\left(\mathrm{CH}_{4}\right), n(\mathrm{CO})$, and $n\left(\mathrm{CO}_{2}\right)$, are indicated in Table S2. $n(\mathrm{CO})$ for $\mathrm{RuO}_{2}$ in $\mathrm{MOB}$ and $n\left(\mathrm{CO}_{2}\right)$ for $\mathrm{FePO}_{4}$ in MOC and MOB could not be derived because these products were not detected. 


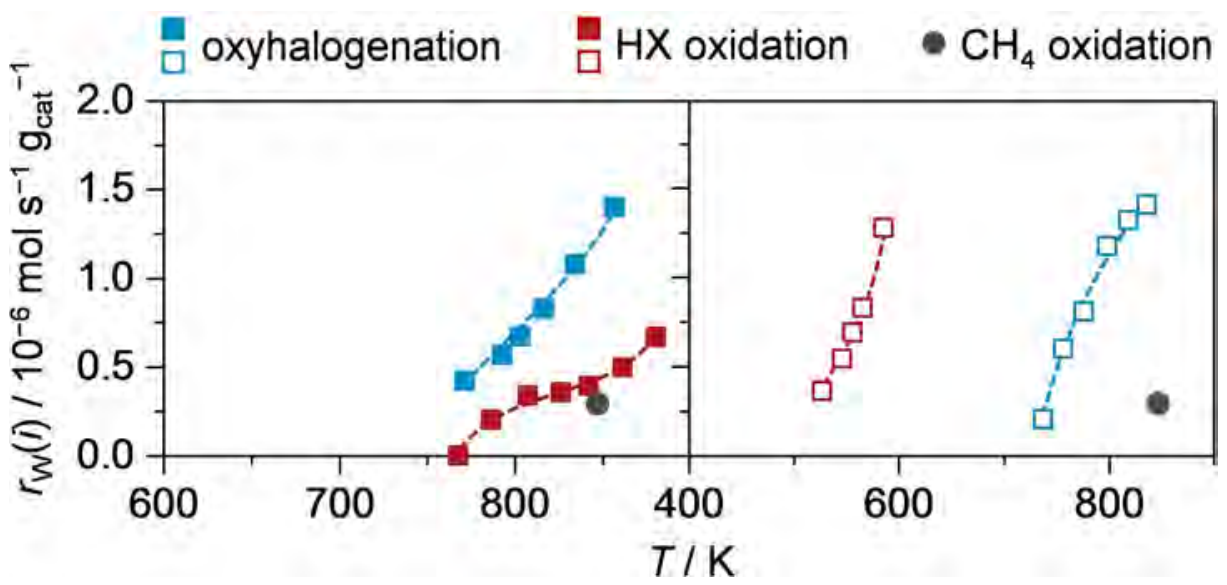

Figure S8. Reaction rate versus temperature in oxyhalogenation (blue), $\mathrm{HX}$ (red), and $\mathrm{CH}_{4}$ (grey) oxidation over $\mathrm{TiO}_{2}$. $\mathrm{X}=\mathrm{Cl}$ : solid symbols; $\mathrm{X}=\mathrm{Br}$ : open symbols. Conditions: $\mathrm{CH}_{4}: \mathrm{HX}: \mathrm{O}_{2}: \mathrm{Ar}: \mathrm{He}=6: 6: 3: 4.5: 80.5$ (blue symbols); $\mathrm{HX}: \mathrm{O}_{2}: \mathrm{Ar}: \mathrm{He}=6: 3: 4.5: 86.5$ (red symbols); $\mathrm{CH}_{4}: \mathrm{O}_{2}: \mathrm{Ar}: \mathrm{He}=6: 0: 3: 4.5: 86.5$ (grey symbols). 


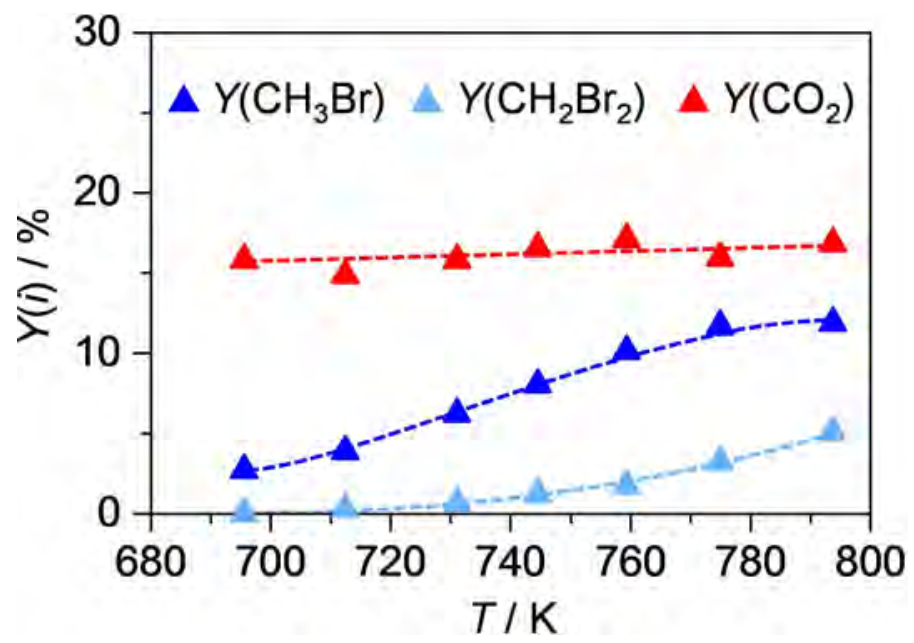

Figure S9. Product yield versus temperature in $\mathrm{MOB}$ over $\mathrm{RuO}_{2}$. Conditions: $\mathrm{CH}_{4}: \mathrm{HBr}: \mathrm{O}_{2}: \mathrm{Ar}: \mathrm{He}=$ 6:6:3:4.5:80.5. 


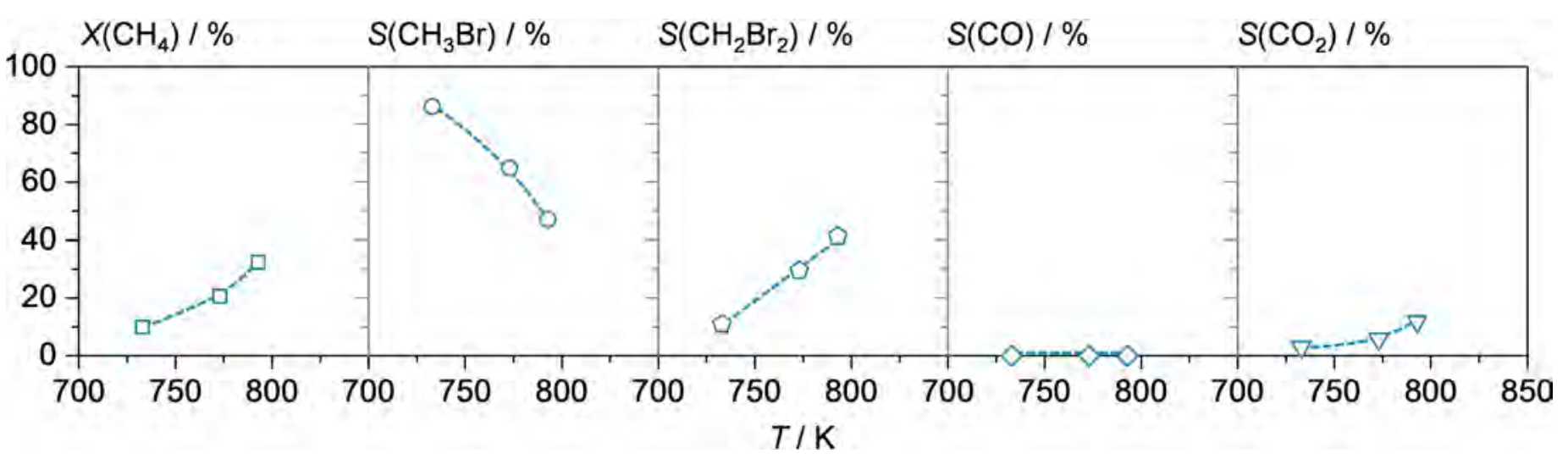

Figure S10. $\mathrm{CH}_{4}$ conversion and product selectivity versus temperature in $\mathrm{MOB}$ over $\mathrm{RuO}_{2}$. Conditions: $\mathrm{CH}_{4}: \mathrm{HBr}: \mathrm{O}_{2}: \mathrm{Ar}: \mathrm{He}=6: 15: 3: 4.5: 71.5$. 

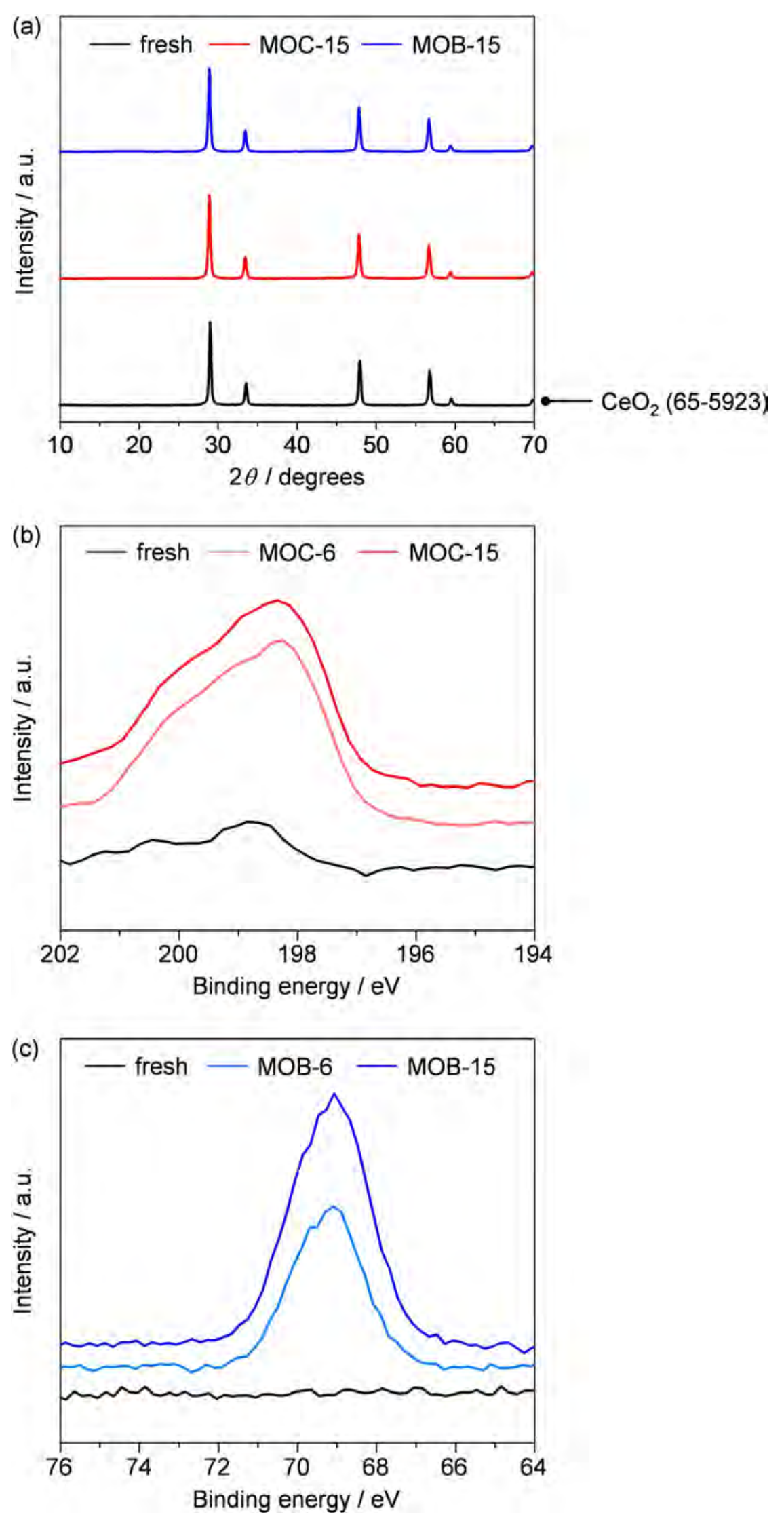

Figure S11. (a) X-ray diffraction patterns, and (b) $\mathrm{Cl} 2 p$ and (c) $\mathrm{Br} 3 d$ core level XPS spectra of the samples prior to (black), and after MOC (blue) and MOB (red). Numbers in the sample code denote the applied feed HX concentration in vol.\% during their exposure to MOC or MOB. 


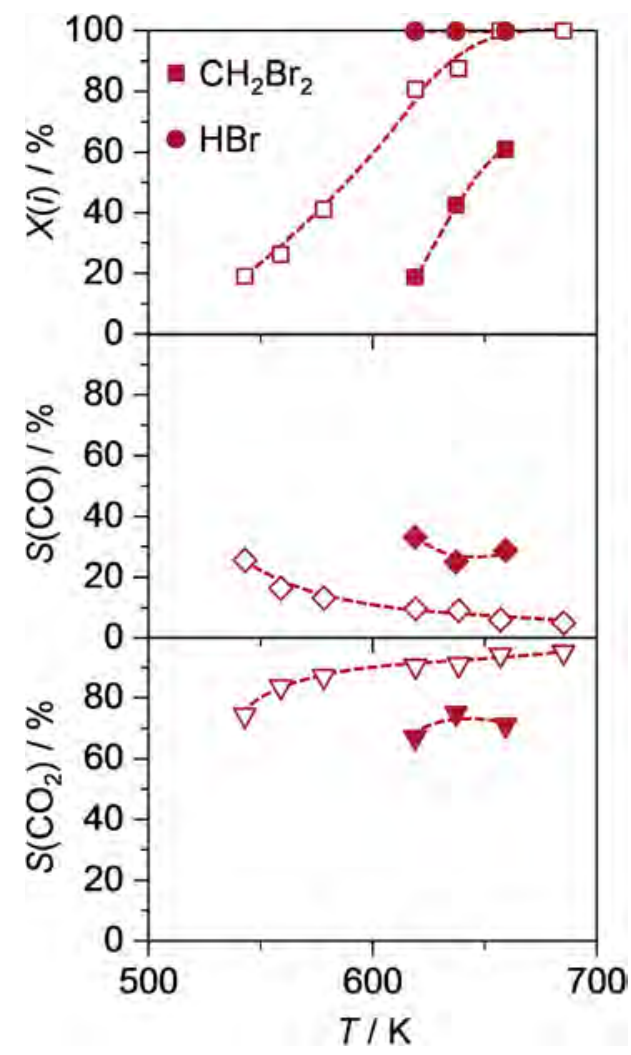

Figure S12. Conversion and product selectivity versus temperature in $\mathrm{CH}_{2} \mathrm{Br}_{2}$ oxidation over $\mathrm{CeO}_{2}$. Conditions: $\mathrm{CH}_{2} \mathrm{Br}_{2}: \mathrm{O}_{2}: \mathrm{Ar}: \mathrm{He}=1: 3: 4.5: 91.5$ (open symbols); $\mathrm{CH}_{2} \mathrm{Br}_{2}: \mathrm{HBr}: \mathrm{O}_{2}: \mathrm{Ar}: \mathrm{He}=1: 6: 3: 4.5: 85.5$ (solid symbols). 


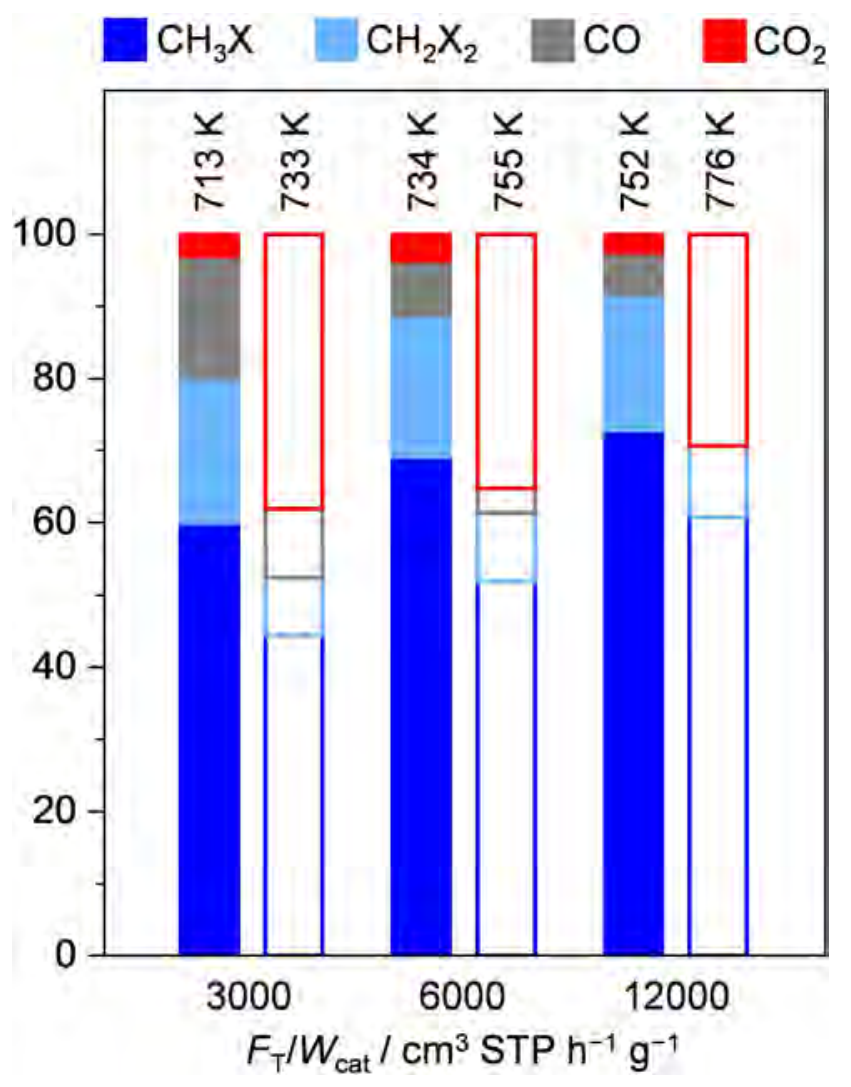

Figure S13. Product selectivity at $c a .18 \% \mathrm{CH}_{4}$ conversion in MOC (solid bars) and MOB (open bars) at different space velocity $\left(F_{\mathrm{T}} / W_{\text {cat }}\right)$ over $\mathrm{CeO}_{2}$. The corresponding reaction temperature is indicated on top of each bar. Conditions: $\mathrm{CH}_{4}: \mathrm{HX}: \mathrm{O}_{2}: \mathrm{Ar}: \mathrm{He}=6: 6: 3: 4.5: 80.5$. 